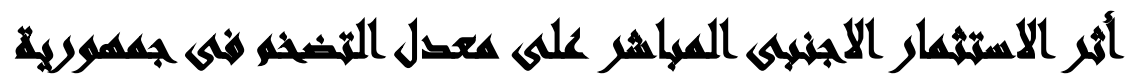

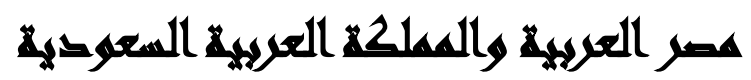

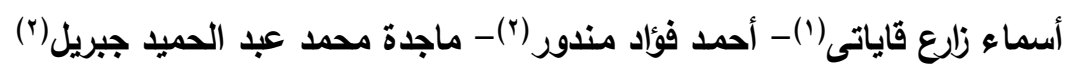

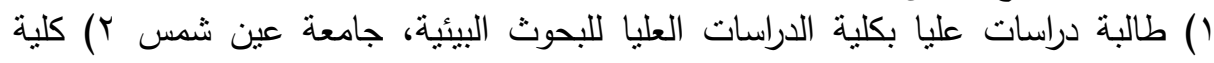

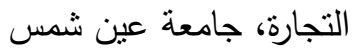

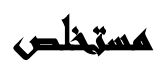

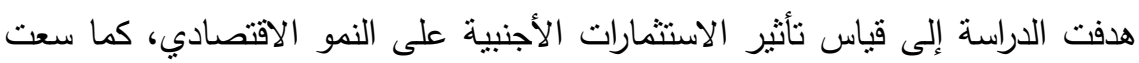

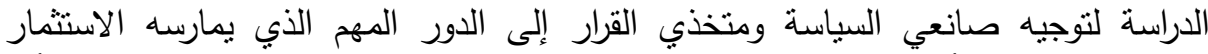

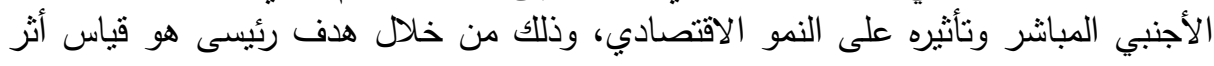

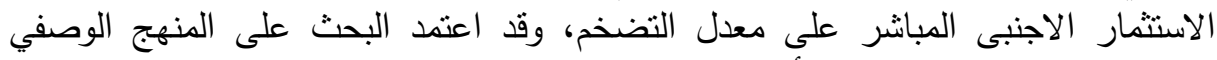

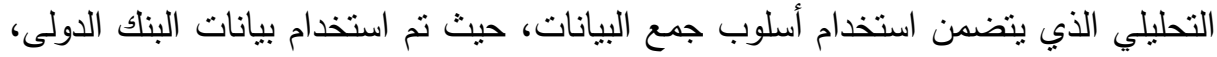

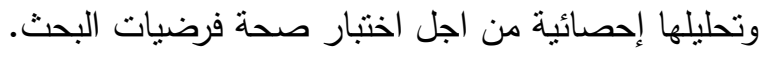
وقد توصل البحث إلى توني • يوجد تأثير معنوي ذو دلونة دلالة إحصائية للاستثمار الاجنبى المباشر على معدل التضخم

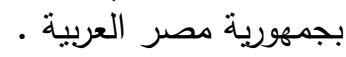
• يوجد تأثير معنوي ذو دلالة إحصائية للاستثمار الاجنبى المباشر على معدل التضخم

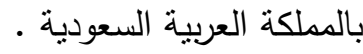

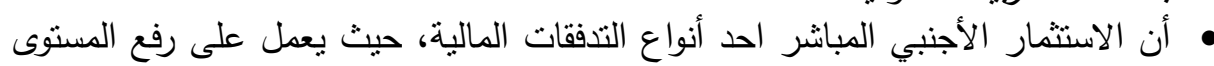

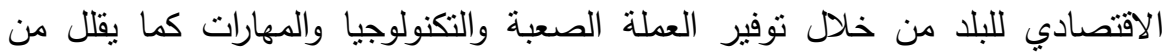

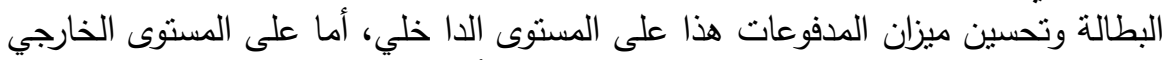

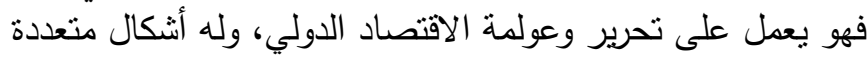

$$
\begin{aligned}
& \text { r.r. المجلد الخمسون، العدد التاسع، الجزء الثالث، سبتمبر } \\
& \text { التزقيم الدولي 0826- ISSN 1110 } \\
& \text { الترقيم الدولي الموحد الإلكتروني 3178-2636-26 }
\end{aligned}
$$


• يجب على الحكومة المصرية العمل الجاد من اجل تحقيق الاستقرار الأمني والسياسي

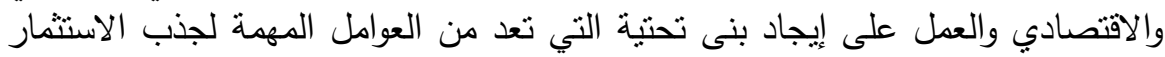

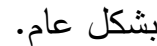
• ضرورة القضاء على الفساد المالي والإداري في دول المقارنة، من خلال تتديد إجراءات هيئة الرقابة الإدارية والمالية على مؤسسات الدولة والتنسيق بينهم، والاطنلاع على النقادية التقارير

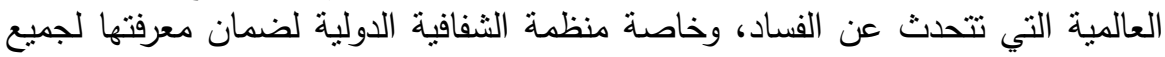

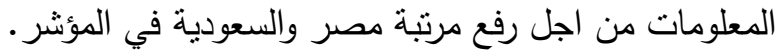

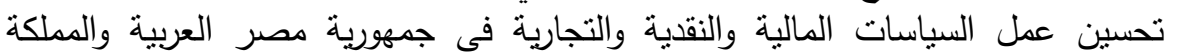

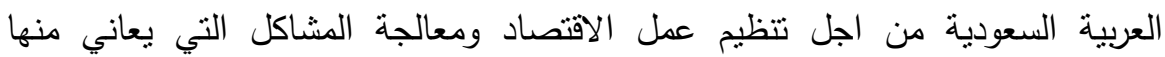
الاقتصاد مثل مشاكل التضخم والبطالة وعجز الموازنة العامة والديون وغيرها. الكلمات المفتاحية: الاستثمار الاجنبى المباشر - معدل التضخم - مصر - النية السعودية وغالية

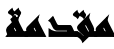

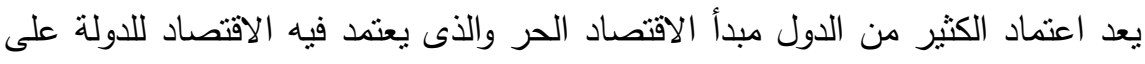

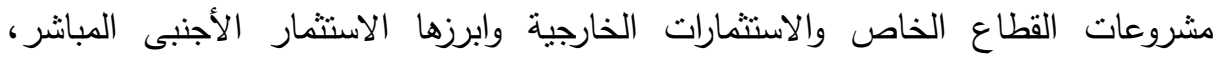

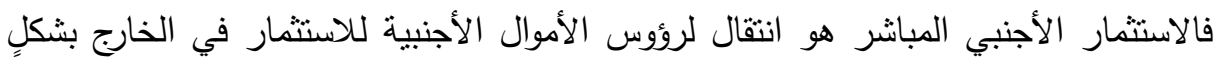

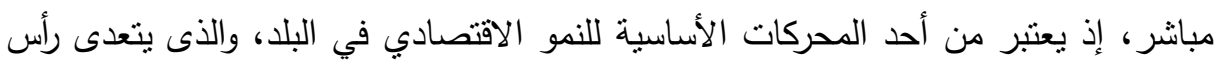

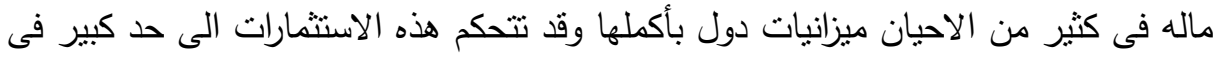
اقتصاد العالم بفضل إستراتيجية تعتمد أساسا على تدويل أنشطتها الإنتاجية والتسويقية، وبناء إستراتيجيات تتسم بالثمولية والتتويع حينا، وبالتركيز والتخصص حينا آخر ، وذلك من خلال الهيمنة على قطاعات النشاط الإستراتيجية المتمثلة في الصناعات الإستخراجية، الصناعات التحويلية والخدمات، وقطاعات الإنتاج والتجارة والمال والمصارف الدولية والاتصالات بغية توزيع المخاطر وتتويع مصادر الربح، لتحويل العالم إلى ساحة اقتصادية واحدة بغية بسط

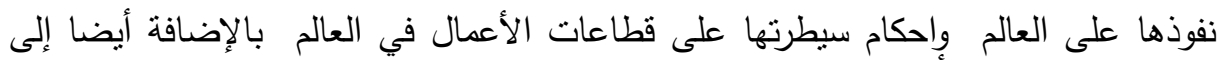

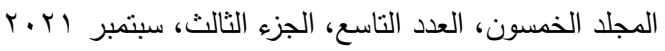

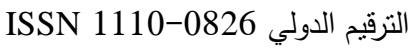

$$
\begin{aligned}
& \text { الترقيم الدولي الموحد الإلكتروني 3178-2636 }
\end{aligned}
$$


ثورتي الاتصالات والمعلوماتية اللتان أسهمتا بقدر كبير في انتشار الثركات متعدية الجنسيات

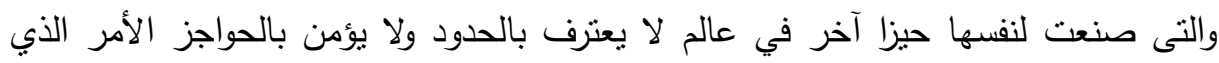

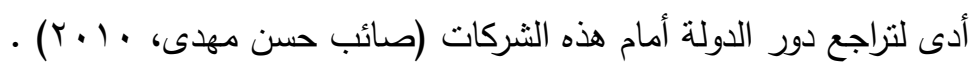

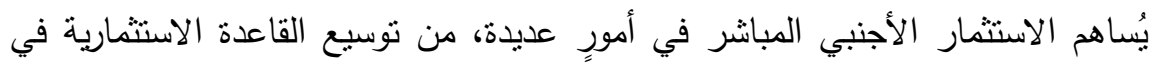

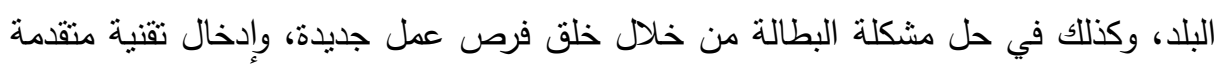

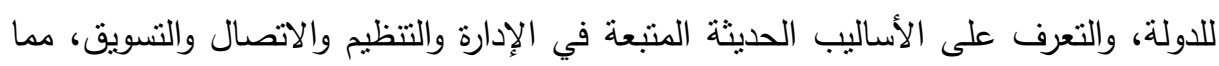
يؤدي إلى كسب العمالة الوطنية مهارة أعلى وخبرة أكبر ، وتُدرك الدول عامةًة بأهمية الاستثمار

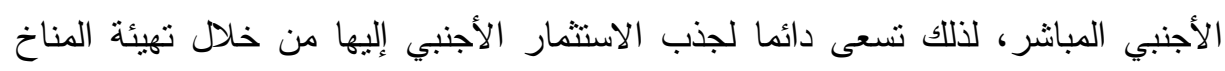
المناسب الذي يحفز على الاستثمار الأجنبي، وتقديم التسهيلات والحوافز للمستثر الأجنبي. إن ظاهرة الاستثمار الأجنبى المباشر أصبحت من المواضيع الهامة لما لها من ثأثثرات

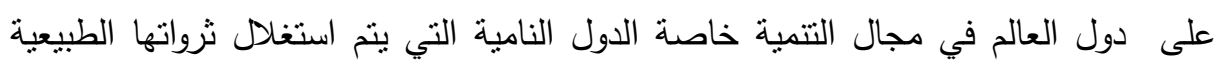

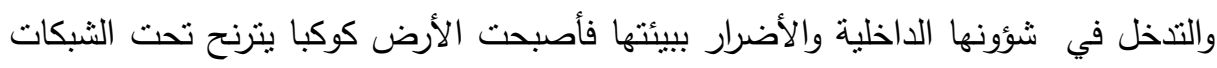

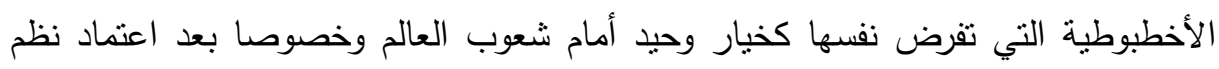

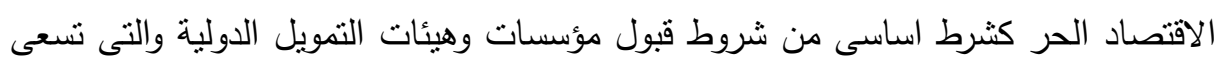
الدول للحصول منها على التمويل اللازم لتمويل المشروعات التتموية الكبرى والتى تخدم فئم اهداف القضاء على الفقر وتحسين الخدمات الصحية والاجتماعية والتعليمية فى الدول النامية

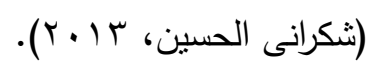

\section{هم:2لة القواسمة}

بات تقرير سياسات الاستثمار الوطنية موجها بصورة متزايدة نحو الاستراتيجيات الانمائية الجديدة، وتحرص معظم الحكومات على اجتذاب الاستثمار الأجنبى المباشر وتسهيل دخوالها

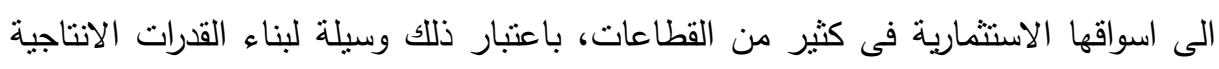

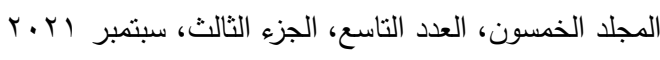

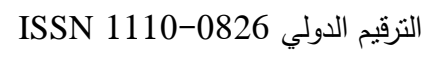

$$
\begin{aligned}
& \text { الترقيم الدولي الموحد الإلكتروني 3178-2636 }
\end{aligned}
$$


بديلا عن الاقتراض او الاقلال منه والسعى الى تحقيق التتمية، وبما ان مفهوم التتمية

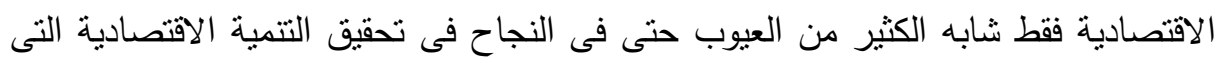
لم تراعى الجوانب الاجتماعية من حيث تقليل معدلات البطالة والتغلب على الفقر والحفاظ

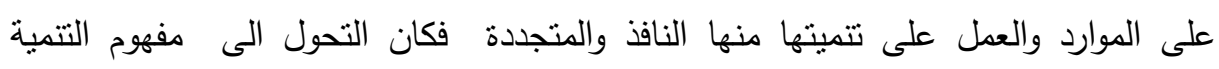
المستدامة كهدف اساسى فى ظل المستجدات على الساحة الدولية واعنبارها كمسار للتتمية

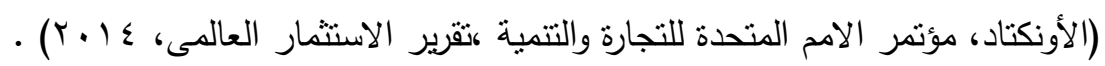

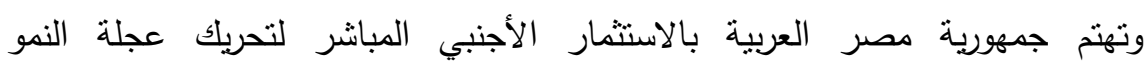

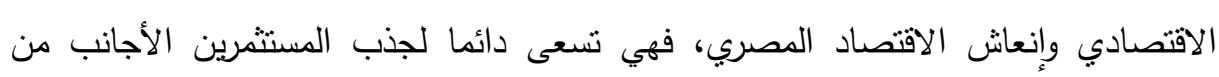

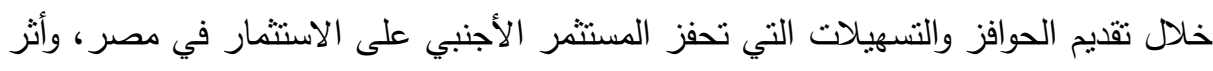
ذللك على الاقتصاد المصرى وبناءً على ذللك يمكن تلخيص مشكلة البحث في التساؤل الآتي: ما أثز الاستثمار الاجنبى المباثر على معدل التضخم فى جمهورية مصر العربية والمملكة العربية السعودية ؟

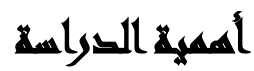

وتكمن أهمية الدراسة فى الانتشار الواسع للاستثمار الأجنبى المباشر وضخامة

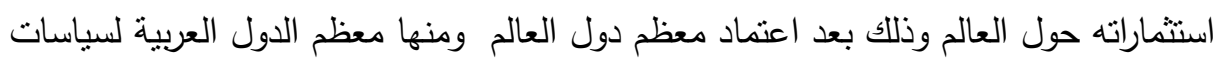
الاقتصاد الحر، واجتهاد الدول فى تقديم الحوافز والتسهيلات لجذب هذه الثركات، ومحاولة

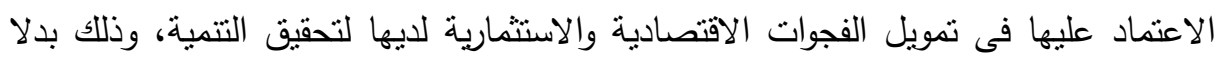

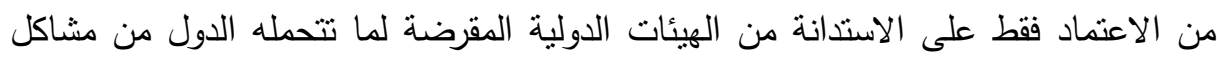

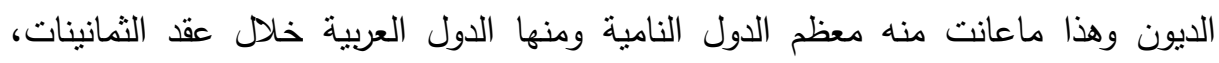
والتعرض للتحديات التى تواجه الاستثمار الأجنبى المباشرفى تحقيق اهدافها من تعظيم

$$
\begin{aligned}
& \text { المجلد الخمسون، العدد التاسع، الجزء الثالث، سبتمبر ا Y.r. } \\
& \text { الترقيم الدولي 0826-0 التئي } \\
& \text { الترقيم الدولي الموحد الإكتروني 3178-2636 }
\end{aligned}
$$


الربحية والنمو والاستمرارية وتحديات تحقيق التتمية فى دول الدراسة المضيفة فى ضوء تننى

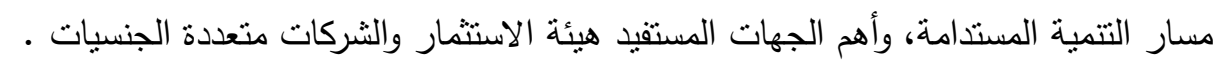

\section{أهماهيه الصوراسلا}

تُساهم الدراسة في نسليط الضوء على أهمية الاستمار الأجنبي من حيث مفهومه

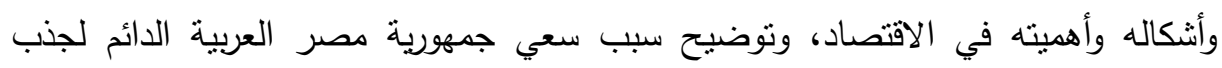

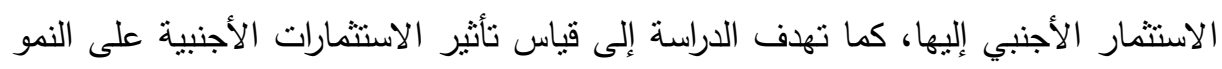

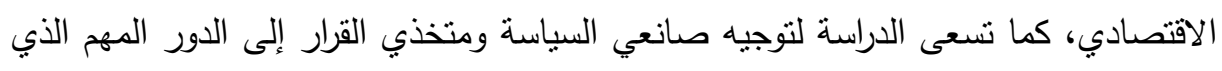

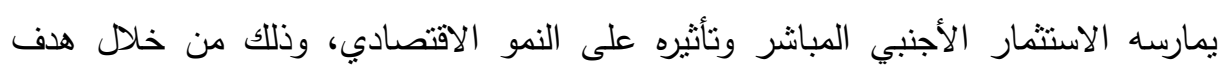

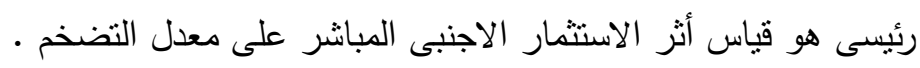

\section{هاروض القواسمة}

ا. لا يوجد تأثثر معنوي ذو دلالة إحصائية للاستثمار الاجنبى المباشر على معدل التضخم

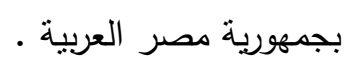

r. لا يوجد تأثنر معنوي ذو دلالة إحصائية للاستثمار الاجنبى المباشر على معدل التضخم

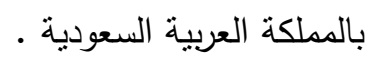

\section{هبور التواسم}

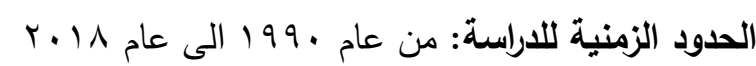

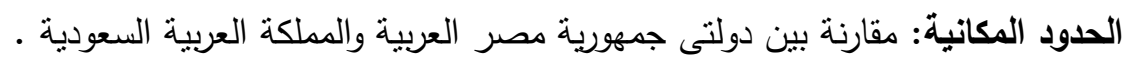

$$
\begin{aligned}
& \text { r.r. المجلد الخمسون، العدد الثاسع، الجزء الثالث، سبتمبر }
\end{aligned}
$$

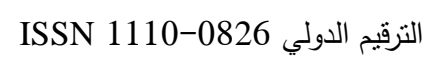

$$
\begin{aligned}
& \text { الترقيم الدولي الموحد الإلكتروني 3178-2636 }
\end{aligned}
$$




\section{هنهبج التراسلة}

تعتمد الدراسة على المنهج الوصفي التحليلي الذي يتضمن استخدام أسلوب جمع البيانات، حيث نم استخدام بيانات البنك الدولى، وتحليلها إحصائية من اجل اختبار صحة

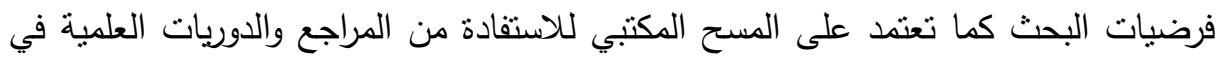
بناء الإطار النظري.

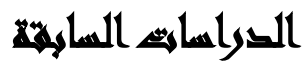

فيما يلى عرض لمجموعة من الدراسات التى أهتمت بالاستثمار الإجنبى المباشر فى

$$
\text { الدول العربية . }
$$

دراسة هشام سالم سليمان ابو عميرة (11 ـ ب): " دور الثركات متعددة الجنسيات

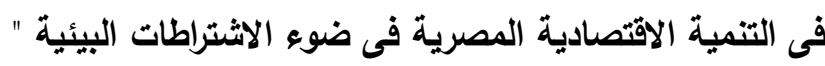

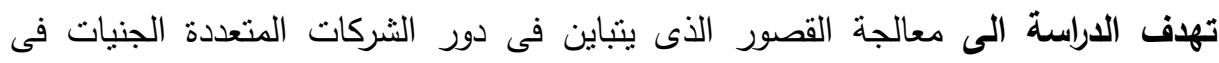
التتمية الاقتصادية فى الدول النامية ودراسة نماذج هذه الثركات الدولية فى قطاع المباه الغازية وهى شركات فى مصر من زمن وقطاع يمثل كثافة عمالة وكثافة راس المال

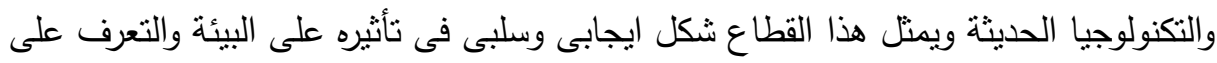
الاضرار الناجمة عن هذا القطاع والتعرف على المقترحات لتجنب هذه الاضرار السلبية ومعالجتها وقد توصلت إلى أن ظاهرة الاستثمار الأجنبى المباشرظاهرة واقعية وحتمية وموجودة فى كل

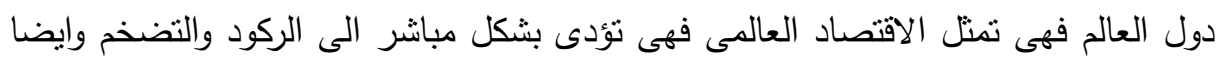

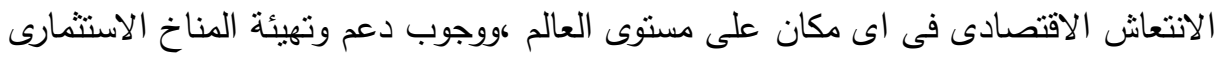

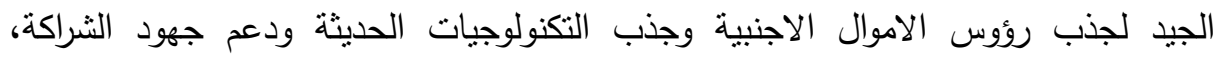

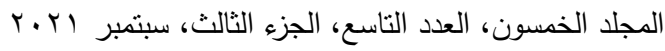

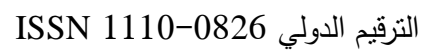

$$
\begin{aligned}
& \text { الترقيم الدولي الموحد الإلكتروني 3178-2636 }
\end{aligned}
$$


والمطلوب من الاستثمار الأجنبى المباشركثير جدا فى حقل المحافظة على البيئة من التلوث ونقل تكنولوجيا نظيفة.

دراسة سامع محمد عبد السلام قتديل (Y Y ب): " دور الاستثمارات الاجنبية

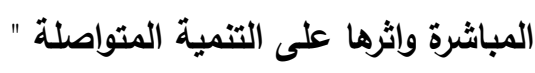
تهاف الاراسة إلى تحديد اهم العوامل المؤثرة على تدفقات الاستثمار الاجنبى المباشر فى مصر واسرائيل من خلال دراسة (المتغيرات الاقتصادية المحلية والاقليمية والدولية على هذه التدفقاتهودراسة توقعات الهيئات الدولية لاداء الاقتصاد المصرى والاسرائيلى خلال فترة

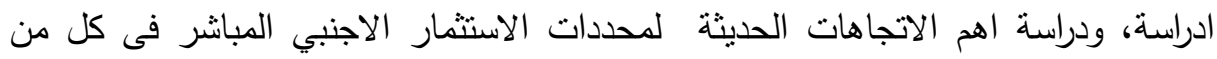
مصر واسرائيل) بهدف اشتقاق دالة الاستثمار الاجنبى المباشر فى مصر واسرائيل .

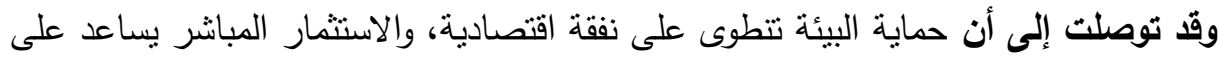
تحقيق التتمية الاقتصادية وانه ليس هناك اتجاه دولى وعالمى كبير للربط بين الاستثمار

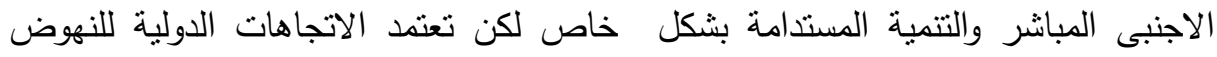
بالتتمية المستدامة من خلال الاضرار والملوثات الناتجة عن الاستثمارات بشكل عام و من لهن خلال تحليل الدراسة للحالة المصرية فيما يخص الاستثمارات الاجنبية المباشرة فى قطاع الاعله

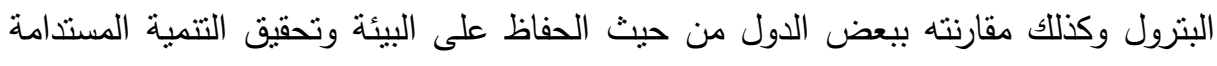
يتضح ان العلاقة بين الاستثمار الاجنبى المبانش والتتمية المستدامة فى جزء كبير منها علاقة

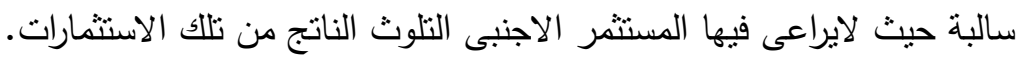

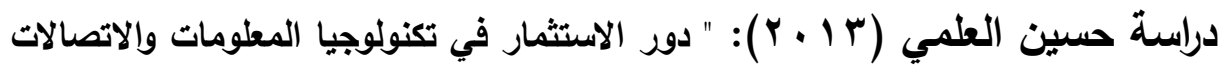
في تحقيق التنمية المستدامة " تهاف الدراسة إلى الوقوف على مجموعة من النقاط يمكن تلخيص أهمها فيما يلي:

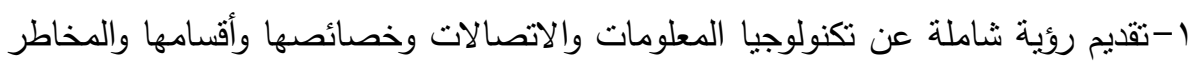

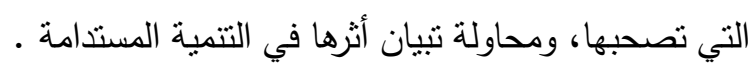

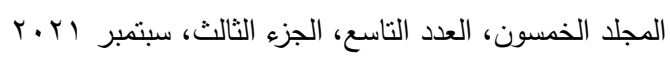

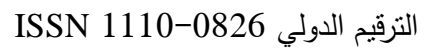

$$
\text { الترقيم الدولي الموحد الإلكتروني 3178-2636 التروب }
$$


r-محاولة تبيان الدور المحوري الذي يقوم به الاستثمار في تكنولوجيا المعلومات والاتصالات في مختلف المجالات التتموية، وكذللك مدى مساهمتها في تحقيق الأهداف الإنمائية للألفية.

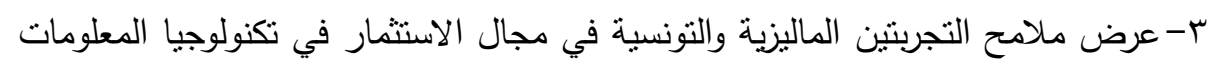

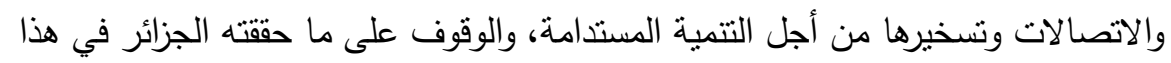
المجال ومدى إمكانية استفادتها من هاتين التجربنين.

$$
\text { وقد توصلت إلى أن: }
$$

ا-1إن تطوير وزيادة الاستثمار في قطاع تكنولوجيا المعلومات والاتصالات وحسن استخدامه وتوظيفه يشكل فرصة ذهبية لافع عجلة التتمية المستدامة، وتحقيق تحسينات في مستويات

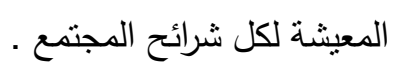

r-إن الأثر الاقتصادي للاستثمار في تكنولوجيا المعلومات والاتصالات يمكن أن يكون من

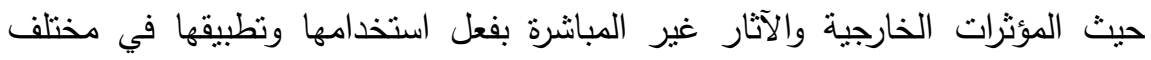

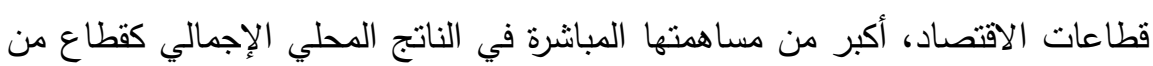

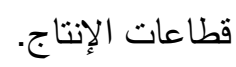

دراسة الهام شيلى (ع ا • ץ): " دور استراتيجية الجودة الثاملة فى تحقيق التثمية المستدامة فى المؤسسة الاقتصادية (دراسة ميدانية فى المؤسسة المينائية بسكيكدة) " تهاف الدارسة إلى ابراز كيفية تحقيق استدامة للمؤسسات الاقتصادية بالاعتماد على اسلوب العابه

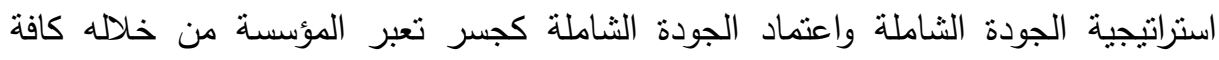
التحديات المتعلقة بالتتمية المستدامة وتسليط الضوء على موضوع الجودة الثاملة كفلسفة استراتيجية من اجل تحقيق التتمية المستدامة وابراز مختلف المفاهيم المتعلقة بها وتبيان قدرتها على اكساب المؤسسات الاقتصادية مكانة لمكافحة كافة التحديات الاقتصادية والاجتماعية

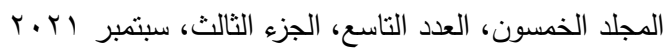

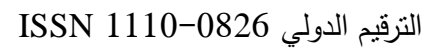

$$
\begin{aligned}
& \text { الترقيم الدولي الموحد الإكتروني 3178-2636 }
\end{aligned}
$$


وقد توصلت إلى أن اى مؤسسة تعتمد تحقيق لمستوى متميز من الجودة على منتجاتها على

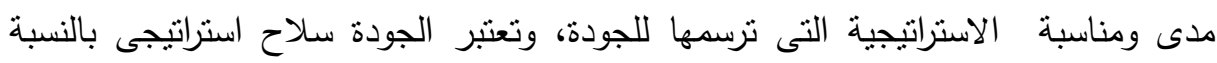
للمؤسسة وذلك لانها تحقق ميزة تتافسية للمؤسسة.

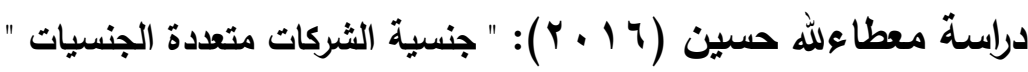
تهرف الدراسة إلى الكثف عن إمكانية تنتع الثركات متعددة الجنسيات بجنسية تتسب من خلاليا إلى دولة معينة وذلك لتحديد النظام القانوني الذي تخضع لو ، ومعرفة ما تتمتع به من إله

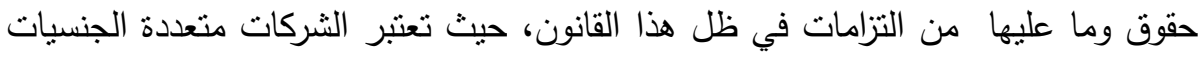

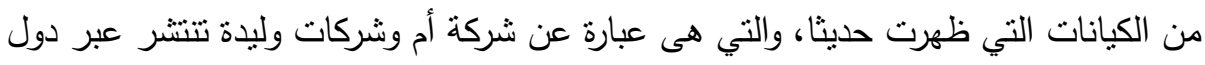
العالم لممارسة مختلف النشاطات التي تتعدى الحدود الإقميمية للاول، فكل وحدة منها تتمتع بجنسية بلد معين والتي تستقل قانونيا عن باقي الوحدات التابعة للشركة الأم، وذللك لمعرفة إلى ولى

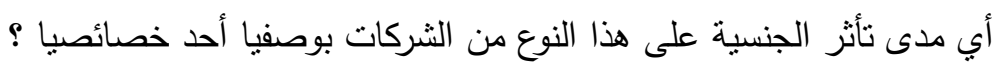
وقد توصلت إلى أن الثركات متعددة الجنسيات أصبحت من أكثر الكيانات تأثنرا في المجات منال الاقتصادي على الساحة الدولية، وذللك لما تملكه من إمكانيات مادية وبشرية هائلة تمتد إلى لئي

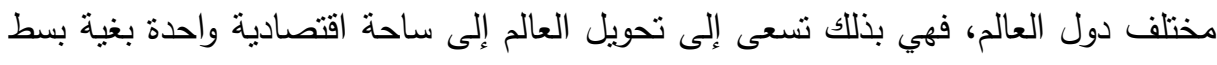

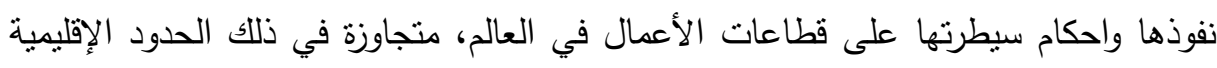

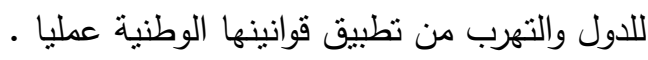
اوجه اختلاف الدراسة عن الدراسات السابقة: يرتبط موضوع الدراسة بالاستثمار الأجنبى

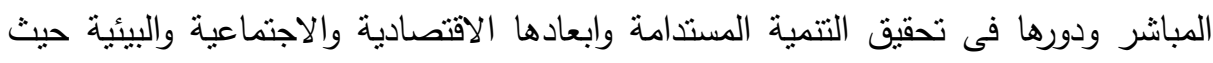
قامت العديد من الدراسات بدورها فى دراسة هذه الاستثمار الاجنبى المباشر، كونه مظهر التهر

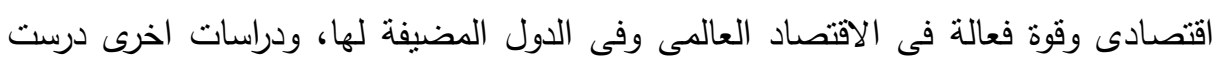

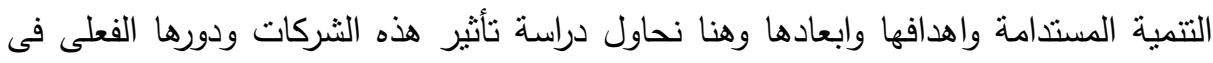

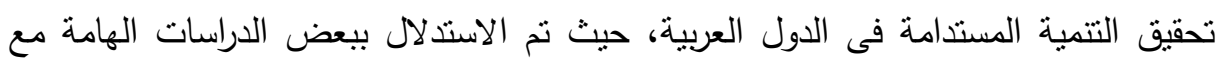

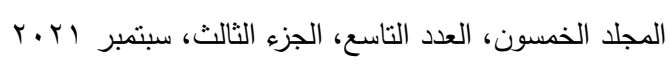

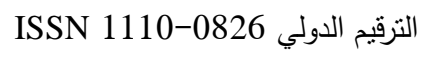

$$
\text { الترقيم الدولي الموحد الإلكتروني 3178-2636 التروب }
$$


ماتتفرد به كل دراسة بخصائصها، وتختلف بانها تدرس دور الاستثمار الأجنبى المباشربما لها

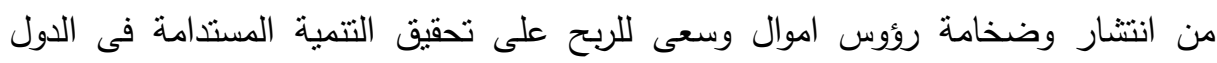

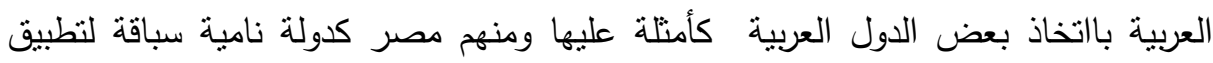

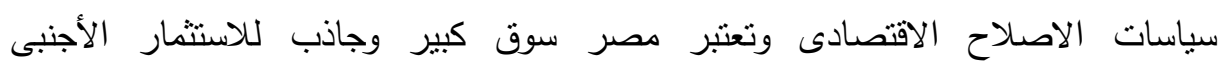
المباشرنظرا لكبر حجم السوق والذى لم يصل الى النتبع بل سوق واعد، ودولة الامارات العربية المتحدة فهى من الدول الناجحة فى استقطاب هذه الثركات بسياستها الانفتاحية

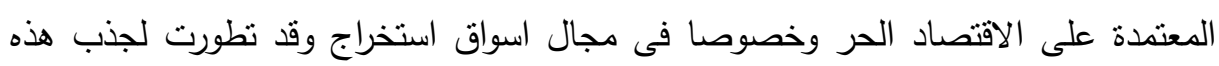
الثركات فى كثير من القطاعات كقطاع الخدمات العامة والمالية والتكنولوجيا والسياحة والتزفيه، ومثال اخر وهى دولة الجزائر والتى تمنل سوق تعدينى كبير يعتمد فى الاساس على لثى

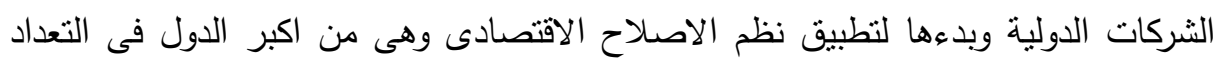

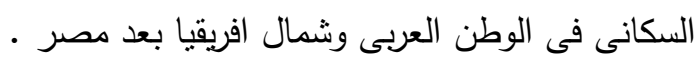

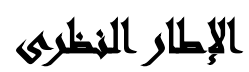

يحظى موضوع الاستثمار الأجنبي المباشر باهتماٍٍ كبير من قبل صانعي القرار، وفي

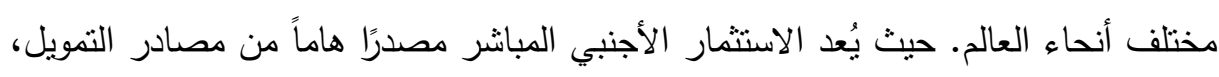

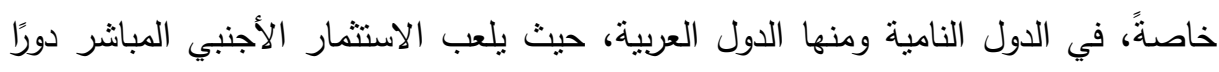
هامًا في دفع عجلة النمو الاقتصادي في هذه الدول.

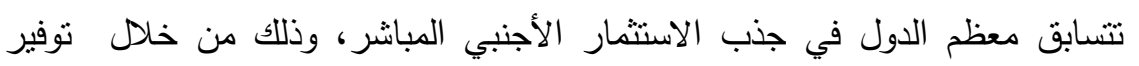

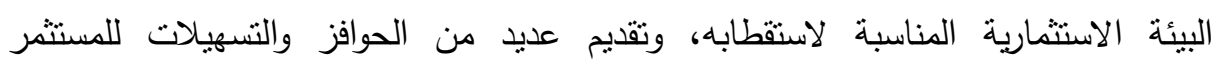
الأجنبي. وسيعرض هذا الفصل نوضيح لـفهوم الاستثمار الأجنبي المباشر وأهميته وأثكاله،

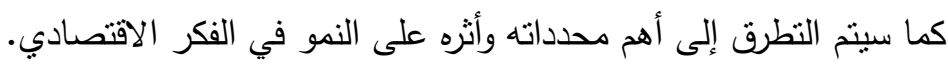




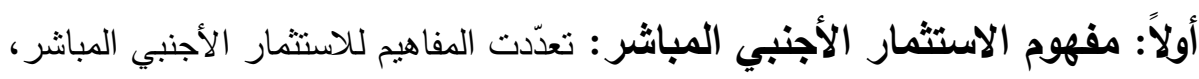

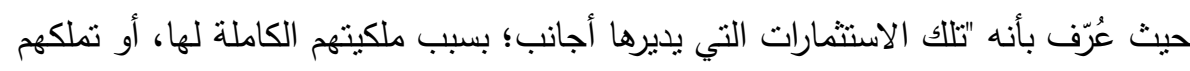

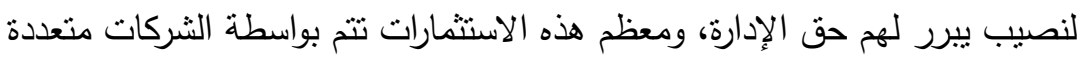

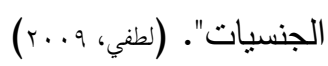

عَرَّن تقرير مؤتثمر الأمم المتحدة للتجارة والتتمية الاستثمار الأجنبي المباثر ، على أنه

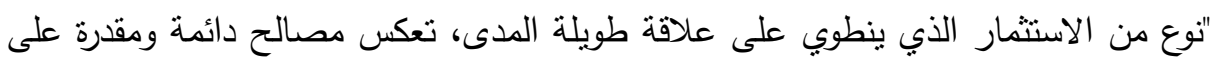

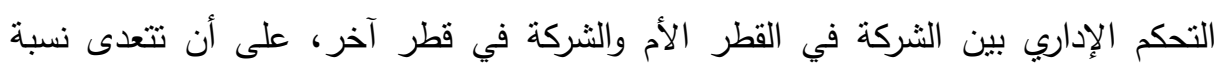

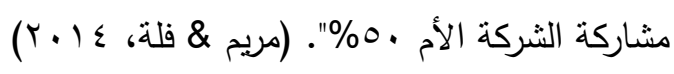

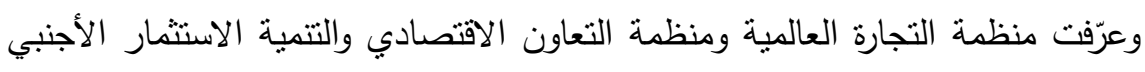

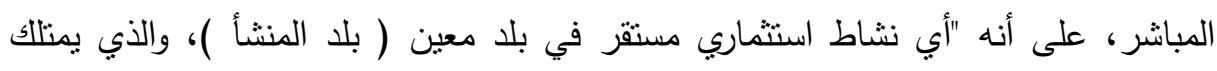

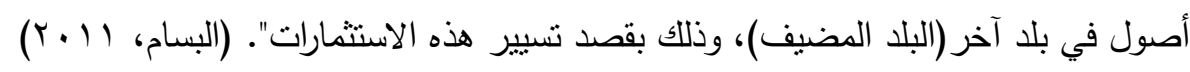

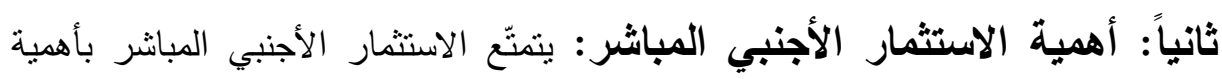

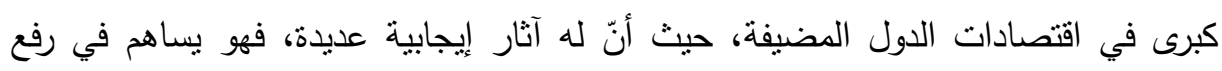

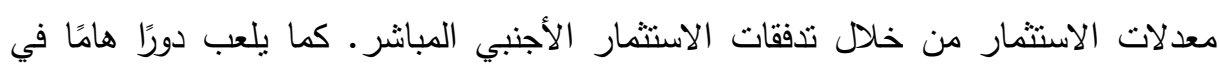

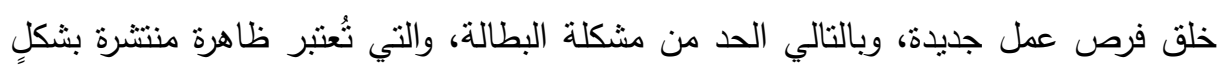

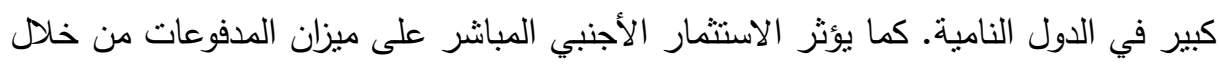

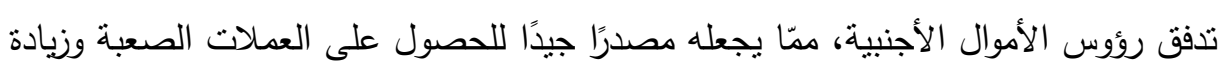

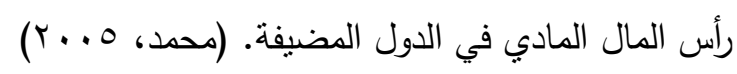

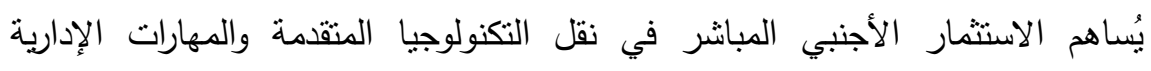
الحديثة للدول المضيفة، والتي لها دور كبير في تطوير مهارة العمال ورفع كفاءة الإنتاج؛ نظرًا

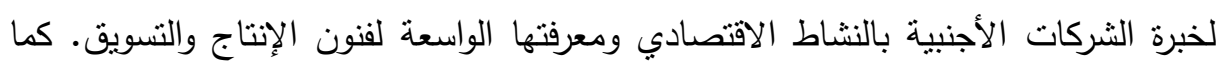

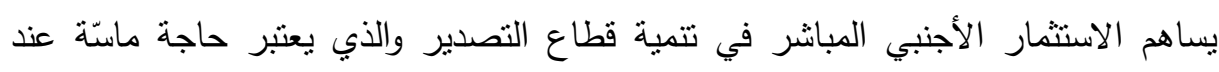

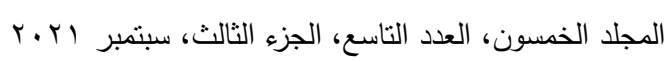

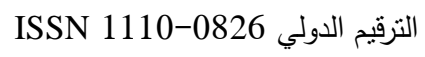

$$
\text { الترقيم الدولي الموحد الإلكتروني 3178-2636 لإني }
$$


الدول النامية، ويزيد الاهتمام بالبحوث والتطوير في الدول المضيفة، بالإضافة إلى أنه يساهم

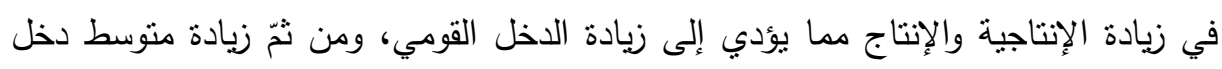

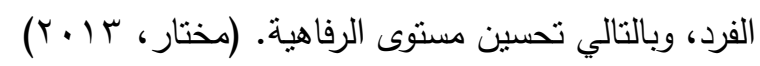
ولكن على الرغم من الآثار الإيجابية التي يجلبها الاستشمار الأجنبي المبانشر، إلآّا أنّ له

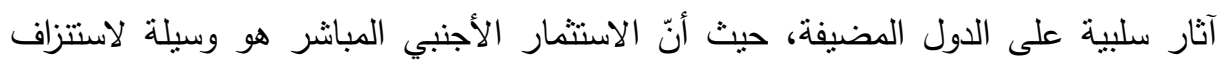

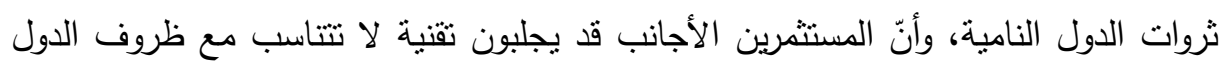

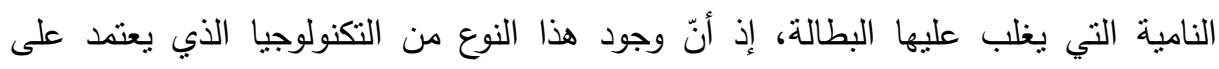

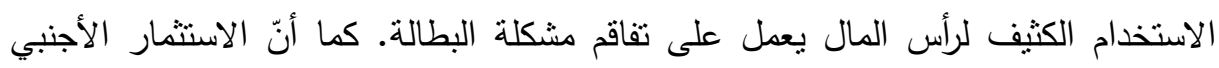

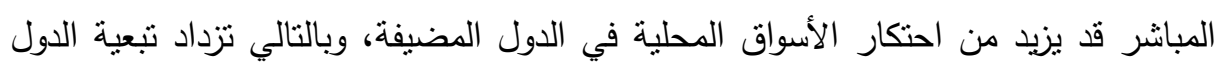

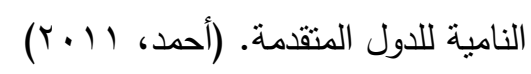

ثُالثاً: أثكال الاستثمار الأجنبي المباشر: يأخذ الاستثمار الأجنبي المباشر أثكالاً

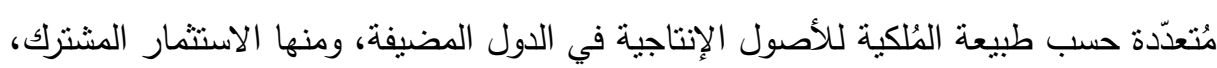

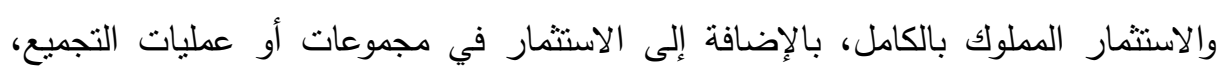

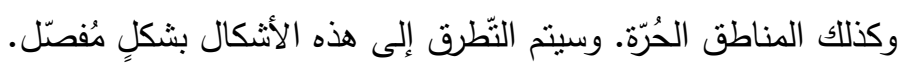
1- الاستثمار المشترك: يُعرَّف الاستثمار المشترك أو كما يسمى أحيانًا بالاستثمارات الأجنبية

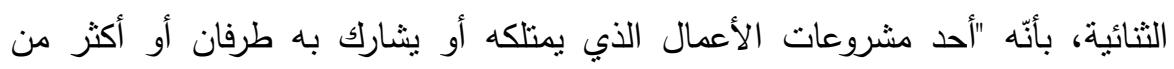

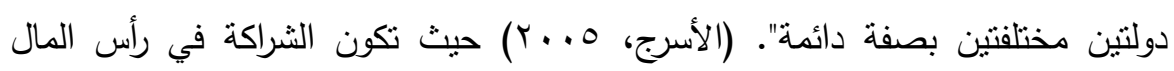

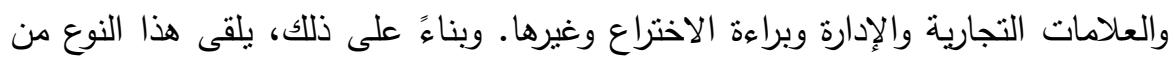

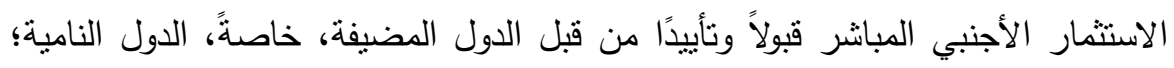

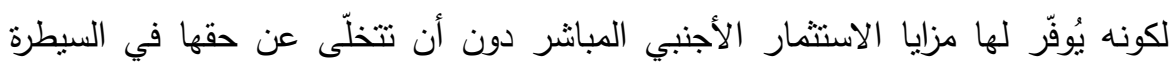

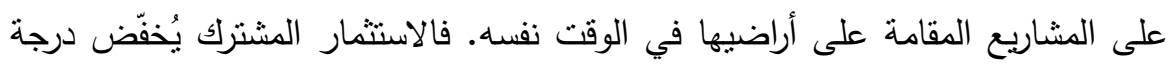
التحكّم من قبل المستثمر الأجنبي، ويساعد على تعزيز الملكية الوطنية.

170

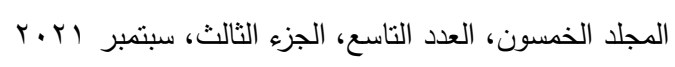

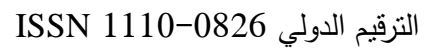

$$
\text { التزقيم الدولي الموحد الإلكتروني 3178-2636 النيم }
$$


r- الاستثمار المملوك بالكامل: يُعتبر هذا الثكل من الاستثمار الأجنبي المباشر الأكثر

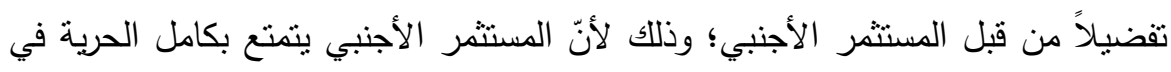

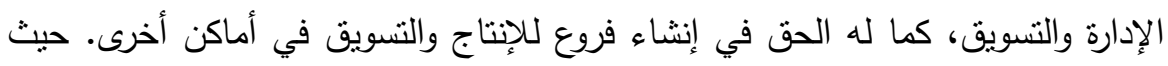

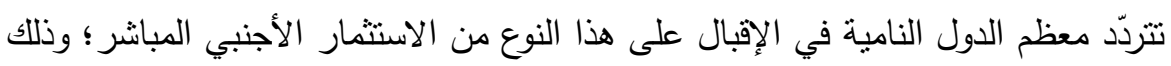

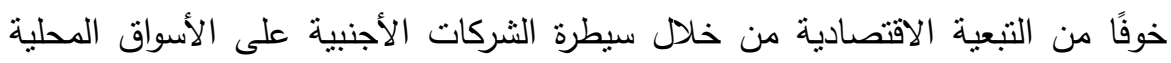

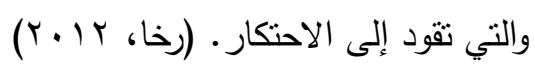

r- الاستثمار في مجموعات أو عمليات التجميع: تأخذ هذه المشروعات شكل الفاقية التافية بين الطرف الأجنبي والطرف المحلي، حيث يقوم الطرف الأجنبي بتزويد الطرف المحلي

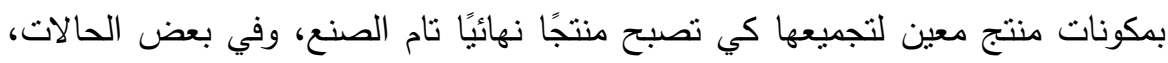
خاصةً، في الدول النامية، يقوم الطرف الأجنبي بتقديم الخبرة والمعرفة اللازمة والمتعلقة بالتصميم الداخلي للمصنع وطرق التخزين والصيانة والتجهيزات الرأسمالية في مقابل عائد

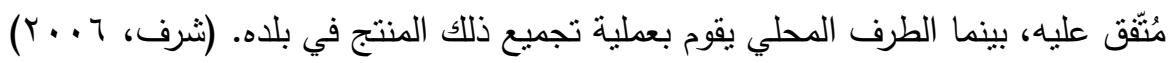

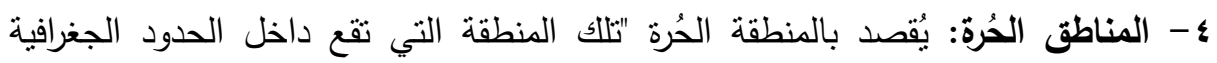
للاولة ولكنها خارج النظام الجمركي لنتلك الدولة، إذ يسمح بدخول الواردات وخروج

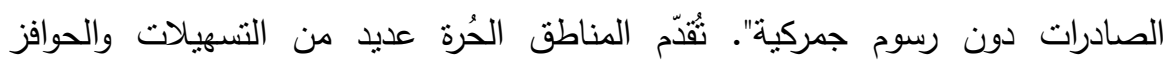

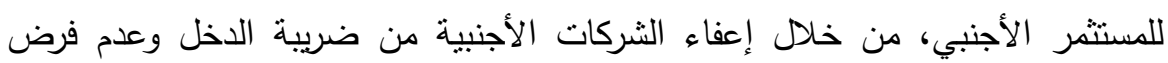
رسوم جمركية على الموارد المستوردة، وتسهيل إقامة العاملين وتوفير الطاقة في تلأك

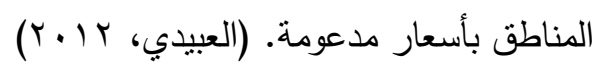
رابعاً: محددات الاستثمار الأجنبي المباشر: تُعتبر المحدّدات الاقتصادية من أهم

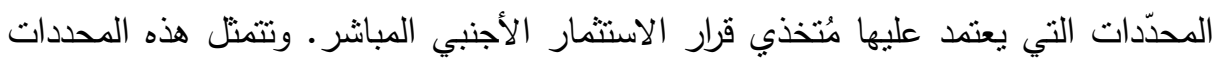

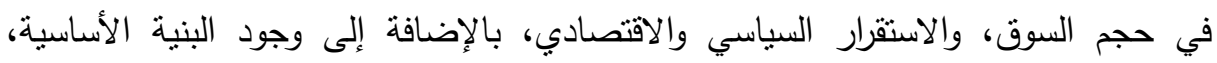

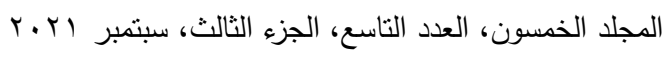

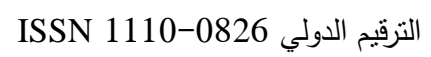

$$
\begin{aligned}
& \text { التزقيم الدولي الموحد الإلكتروني 3178-2636 }
\end{aligned}
$$


ووجود إطار تشريعي ونتظيمي، وكذلك وجود نظام قضائي، إلى جانب تقديم الحوافز المالية والتمويلية للمستثر الأجنبي.

يُعتبر حجم السوق من أكثر المحددات التي تؤثر على قرار المستثمر الأجنبي، فكلما

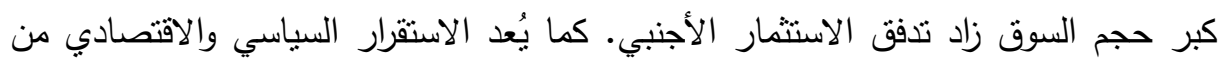
العناصر الأساسية والضرورية في جذب الاستثمار الأجنبي المباشر ، فوجود بيئة مستقرة وآمنة

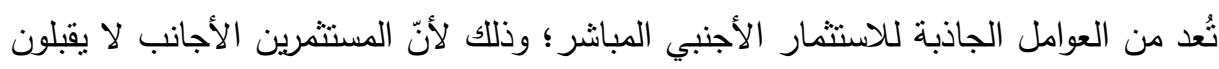
بالمخاطرة برؤوس أموالهم في بيئة تتّّم بعد الاستقرار قد تؤدي بهم إلى الى الخسارة. (صالح،

كما تساهم البنية الأساسية كالطرق ووسائل النقل والمطارات وشبكات الكهرباء في جذب

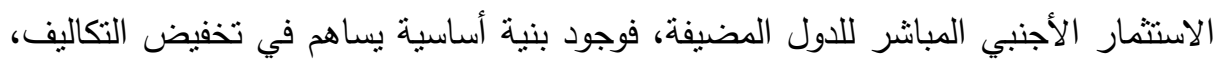

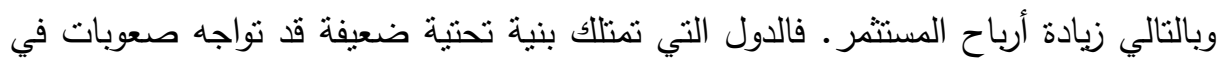

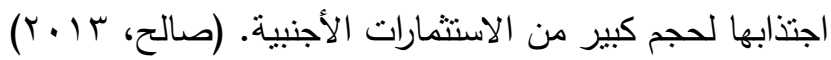

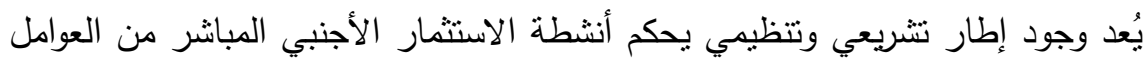
المهمة التي تُحفز على الاستثمار ، إذ يساعد وجود قانون موحد للاستثمار يتُّم بالوضوح

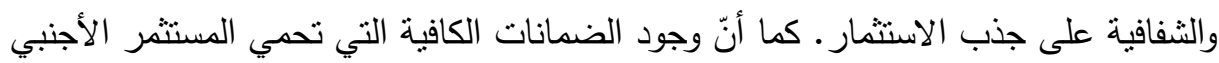
من المخاطر التي قد يتعرض لها في الدول المضيفة مثل التأميم وغيره، من العومل المهمة

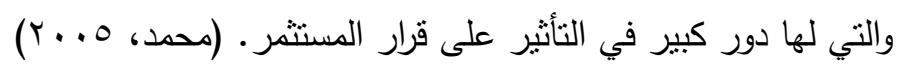
بالإضافة إلى وجود نظام قضائي مستقل يتمتع بالقدرة على تتفيذ القوانين والتعاقدات، لئل وقادر على حل المنازعات التي قد تتشأ بين المستثر الأجنبي والدول المضيفة بكفاءةٍ عالية وبنزاهةٍ محايدة، من العوامل المؤثرة على قرار المستثمر الأجنبي. كما يساهم تقديم الحوافز

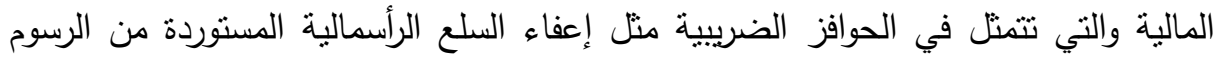

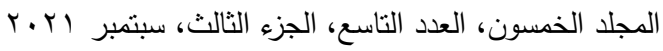

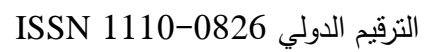

$$
\begin{aligned}
& \text { الترقيم الدولي الموحد الإلكتروني 3178-2636 }
\end{aligned}
$$


الجمركية، وكذللك الحوافز التمويلية مثل الإعانات الحكومية المباشرة، في جذب الاستثمار

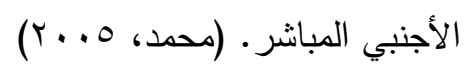

خامساً: أثر الاستثمار الأجنبي المباشر على النما لنمو في الفكر الاقتصادي: إنّ

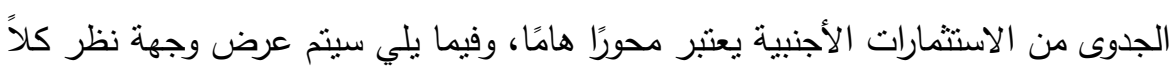

$$
\text { من الفكر الكلاسيكي والفكر النيوكلاسيكي في هذا الخصوص. }
$$

1- الفكر الكلاسيكي: يُعد الاستثمار الأجنبي المباشر وسيلة لتوجيه المدخرات إلى الاستثمار

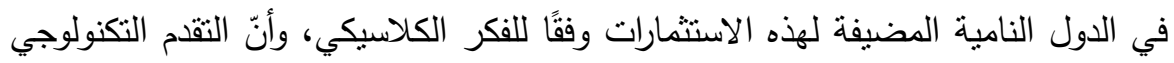
الذي يجلبه الاستثمار الأجنبي المباشر يلعب دورًا هامًا في التأثير على معدل النمو

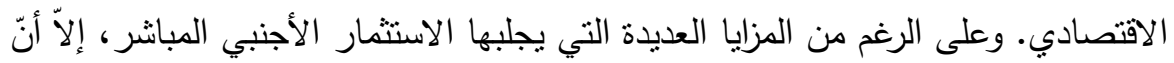

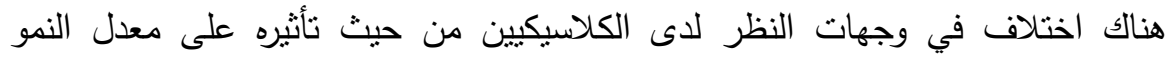
الاقتصادي. حيث يرى البعض أنّ الاستثمار الأجنبي المباشر يؤثر إيجابًا على النمو هوني

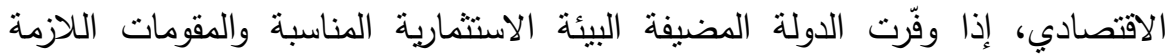

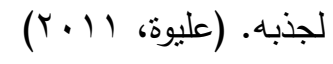

ץ- الفكر النيوكلاسيكي: يرى الفكر النيوكلاسيكي أنّ التقدم التكنولوجي له أنز إيجابي على إنى

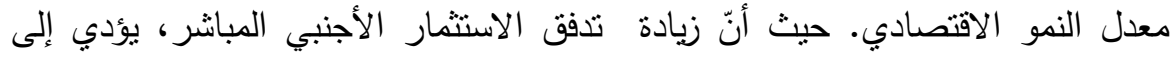

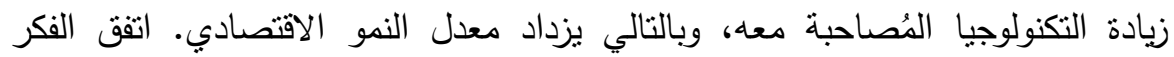
النيوكلاسيكي مع الفكر الكلاسيكي على أهمية الاستثمار الأجنبي المباشر في حقن لاندان

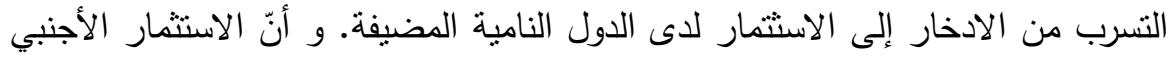

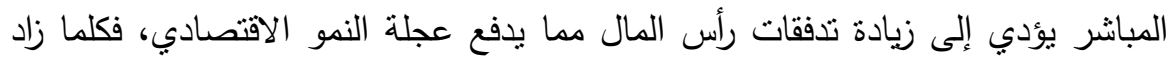

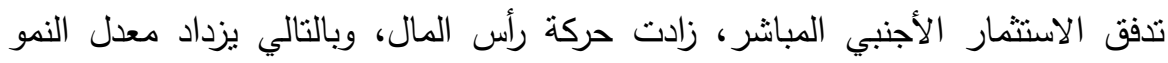

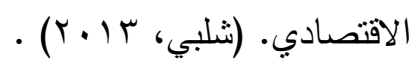

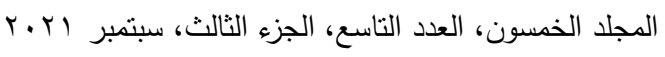

$$
\begin{aligned}
& \text { التزقيم الدولي 0826- ISSN 1110 } \\
& \text { الترقيم الدولي الموحد الإلكتروني 3178-2636-26 }
\end{aligned}
$$


سادساً: التضخم فى الأسعار: يعكس التضخم كما يقيسه مؤشر أسعار المستهلكين

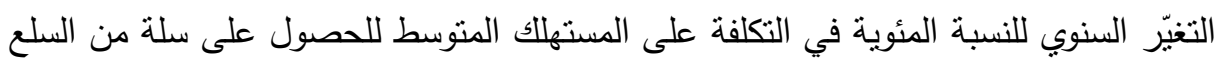

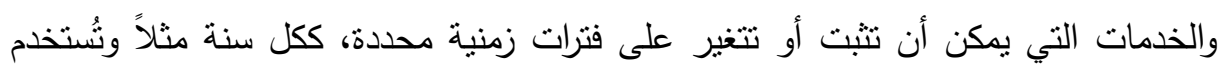
بوجه عام صيغة لاسبيرز ( صندوق النقد الدولي، الإحصاءات المالية الدولية، وملفات

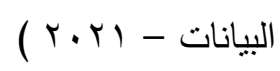
يشير التضخم كما يقيسه معدل النمو السنوي لمعامل التكميش الضمني لإجمالي الناتج

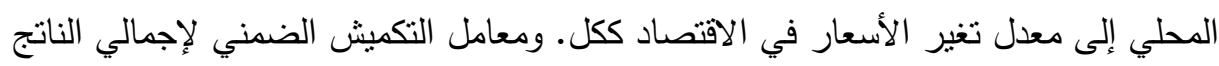
المحلي هو نسبة هذا الإجمالي بالأسعار الجارية للعملة المحلية إلى الإجمالي بالأسعار الثابنة للعملة المحلية ( بيانات الحسابات القومية للبنك الدولي، وبيانات الحسابات القومية لمنظمة

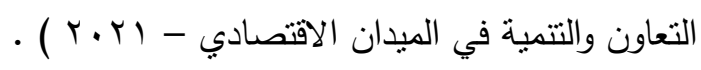

\section{التراسمة الميدانية}

تتاول الباحثون منهجية البحث تفصيلاً للأسس المنهجية التي استتجها في إعداد الدراسة، ويشمل ذلك تحديد نوع ومصادر البيانات، وأسلوب جمع البيانات، وأساليب التحليل

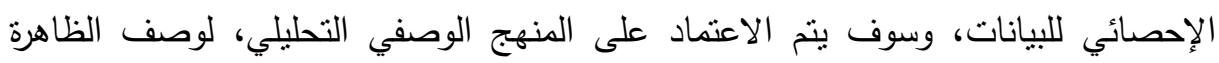
موضوع الدراسة وتحليل بياناتها وبيان العلاقة بين مكوناتها، واستعراض نتائج الدراسة التحليلة ومناقتشها من خلال فروض الدراسة، لتحديد ما إذا كان هناك تأثير معنوى ذو دلالة إحصائية

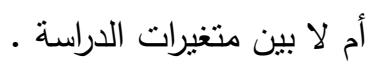

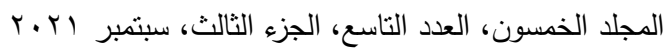

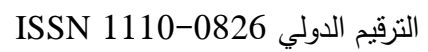

$$
\begin{aligned}
& \text { الترقيم الدولي الموحد الإكتروني 3178-2636 }
\end{aligned}
$$




\section{أولاً: منهج الدراسة واجراء|تها:}

ا - منهج الدراسة: تم الاعتماد على المنهج الوصفي التحليلي، لوصف الظاهرة موضوع الدراسة وتحليل بياناتها وبيان العلاقة بين مكوناتها، وينسم هذا المنهج بأنه يقرب نتائج الدراسة من الواقع ويمكنها من وصف الظواهر بشكل دقيق.

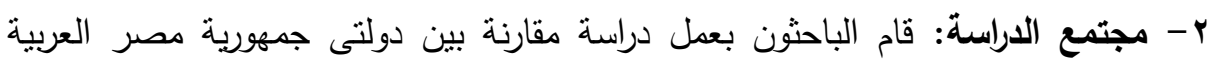

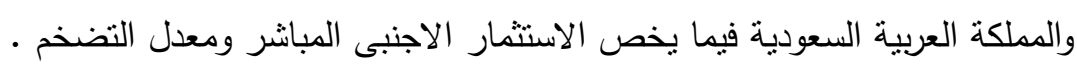

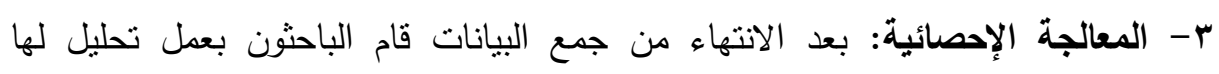

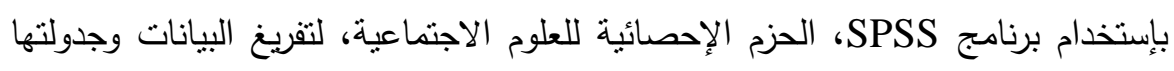

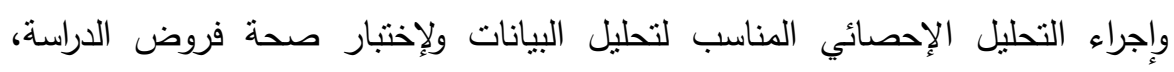
وتطلب ذلك تطبيق بعض أساليب الإحصاء الوصفي والإحصاء التحليلي كالآتي :

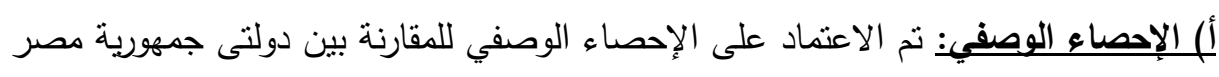

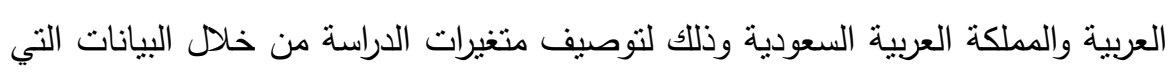
تم جمعها ب) الإحصاء الاستدلالي: اعتمد الباحثون فى تحليل بيانات الدراسة على أساليب الإحصاء

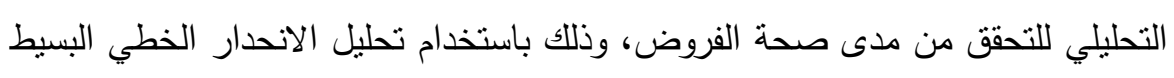

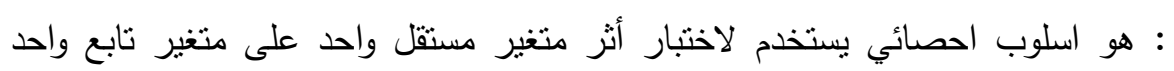

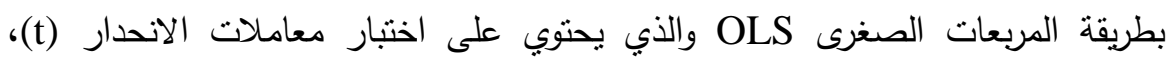

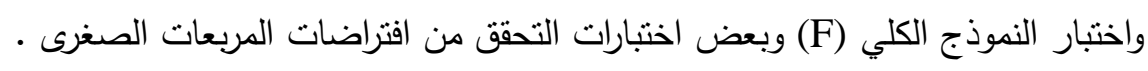
ثانياً: الاحصاء الوصفي لنتائج الدراسة الميدانية: فيما يلي عرض لنتائج الاحصاء الوصفي لمتغيرى وهما: ( الاستثمار الاجنبى المباشر - معدل التضخم فى الاسعار وذلك الكي

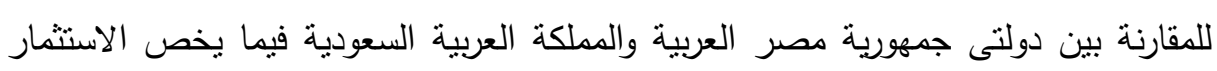

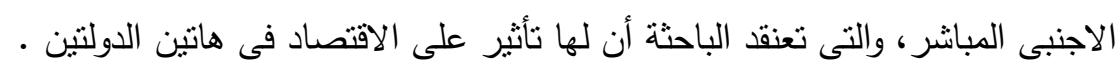

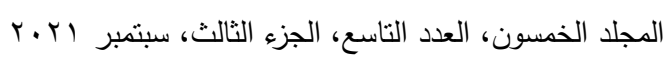

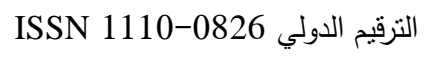
الترقيم الدولي الموحد الإلكتروني 3178-2636 
1- التدفقات فى الاستثمار الأجنبي المباثر: الجدول التالى يوضح الدفقات فى الاستثمار

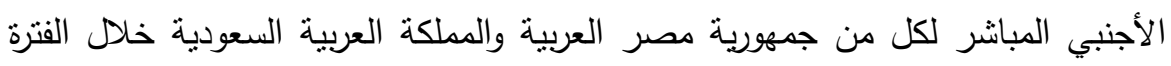

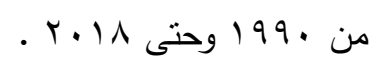

جدول(1): الدفقات فى الاستثمار الأجنبي المباشر لكل من جمهورية مصر العربية والمملكة

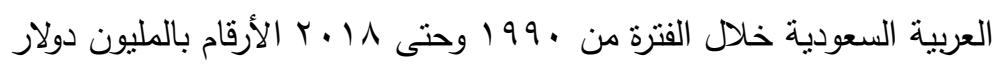

\begin{tabular}{|c|c|c|c|c|}
\hline الزرقم الإياسى & المملكة العربية السعوبية & الزرقم الألياسىى & جمهوبة هصر العربية & السنة \\
\hline $1 \cdots$ & 1, 1גוזיז & 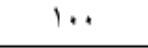 & $V T \varepsilon$ & 199. \\
\hline $11, \vee\urcorner 1$ & ז\&१, ז & $1 \mathrm{~V} 1,11 \mathrm{~V}$ & 1507 & $199 \varepsilon$ \\
\hline$r T \cdot, 1 Y q$ & \&YAT, \{רV & $1\{7,09\{$ & 1.17 & 1991 \\
\hline$r r, 99 \varepsilon-$ & רह, & $A \lambda, 1 \Gamma \varepsilon$ & $7 \varepsilon\urcorner, 9$ & r..r \\
\hline $9 \wedge r, \vee 99$ & IAYqT,IVT & $1 \% 7 \wedge$, rYq & $1 \cdots\{Y, \wedge$ & Y.. T \\
\hline $10 \mathrm{~V}, 0 \mathrm{YO}$ & rqYTr,V.V & 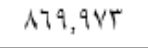 & $2 \pi \times 0,7$ & $r .1$. \\
\hline$\varepsilon \Gamma \cdot, \varepsilon T$ & $\Lambda .11, \mathrm{VAV}$ & רזה, & $\{ר \mid r, Y$ & $Y \cdot 1 \varepsilon$ \\
\hline YYA,IV & $\varepsilon Y\{Y, 1, Y$ & $11+9,179$ & $\Delta \backslash \varepsilon 1, \Gamma$ & $Y .11$ \\
\hline
\end{tabular}

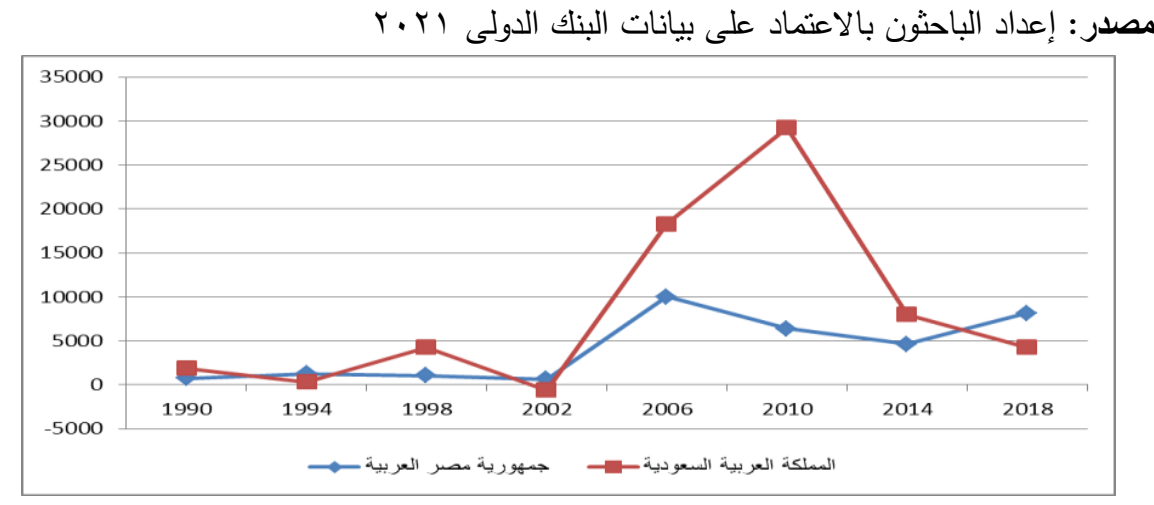

شكل(1): التدفقات فى الاستثمار الاجنبى المباشر لكل من جمهورية مصر العربية والمملكة

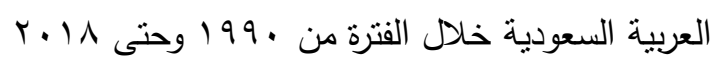

176

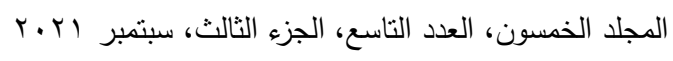

الترقيم الدولي 0826-1110

$$
\text { الترقيم الدولي الموحد الإلكتروني 3178-2636 }
$$


من الجدول (1) والثكل (1) يتضح أنه بمقارنة التدفقات فى الاستثمار الاجنبى المباشر

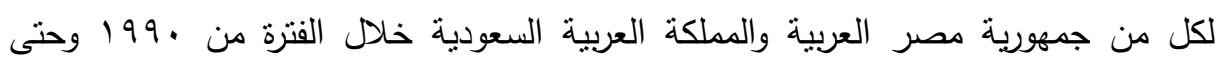

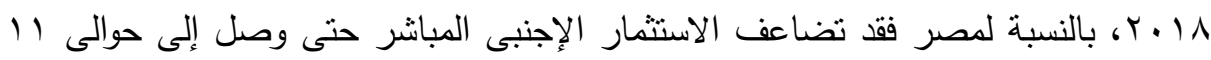

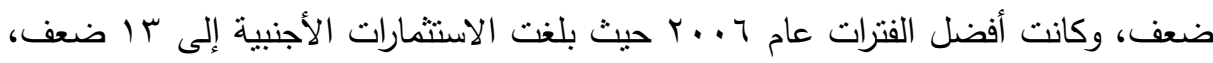

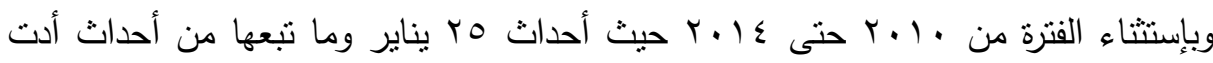
إلى انحصار الاستثمار الاجنبى عن مصر ثم عاد بعد ذلك للإزتفاع بصورة جيدة، أما بالنسبة

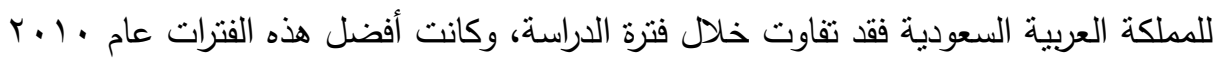
حيث بلغت 10 ضعف، إلا أنها اخفضت بعد ذلك ووصلت إلى الضعفين فقط فى نهاية الفترة. r- معدل التضخم: الجدول التالى يوضح معدل التضخم لكل من جمهورية مصر العربية

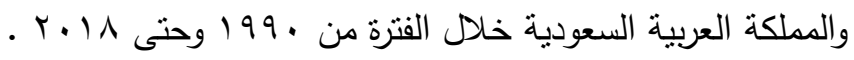
جدول(ץ): معدل التضخم لجمهورية مصر العربية والمملكة العربية السعودية خلال الفترة وحنه

\begin{tabular}{|c|c|c|c|c|}
\hline الرقم القياسى & المملكة العربية السعودية & الرقم القياسى & مصز العربية & السنة \\
\hline $1 \ldots$ & $T, \cdot V V$ & $1 \ldots$ & $17, \vee 07$ & 199. \\
\hline$r V, 17 \lambda$ &., $07 \varepsilon$ & $\varepsilon \Lambda, 7 \tau \mu$ & $1,10 \leqslant$ & 1998 \\
\hline$\overline{T \vee}, \wedge \vee \varepsilon-$ & $\cdot, r \vee V I-$ & $r r, 111$ & $\Gamma, \wedge \vee r$ & 1991 \\
\hline $11,9 \ldots$ & $\cdot, Y \leqslant V$ & 17, & $r, V T V$ & $r \ldots r$ \\
\hline $1 \cdot 7, r \leqslant q$ & $r, Y, q$ & $\{0, T Y Y$ & $V, T \leq 0$ & $r \ldots T$ \\
\hline TOV,.00 & $0, r \mu q$ & $T V, Y Y q$ & 11,570 & r. . . \\
\hline $1 \cdot V, 771$ & T,YMT & $7 ., .91$ & $1 \cdot, \cdot V \cdot$ & 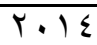 \\
\hline IN & $r, \varepsilon O \Lambda$ & $10,9 \leq 7$ & $\mid \varepsilon, \varepsilon \cdot 1$ & $r .1 \Lambda$ \\
\hline
\end{tabular}

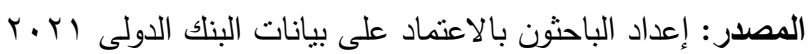

المجلد الخمسون، العدد التاسع، الجزء الثالث، سبتمبر ا ب.r.

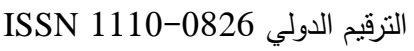

الترقيم الدولي الموحد الإلكتروني 3178-2636 
مجلة العلوم البيئية - مالية

كلية الدراسات العليا والبحوث البيئة - جامعة عين شس الئس

أسماء زارع قاياتى وآخرون البانيا

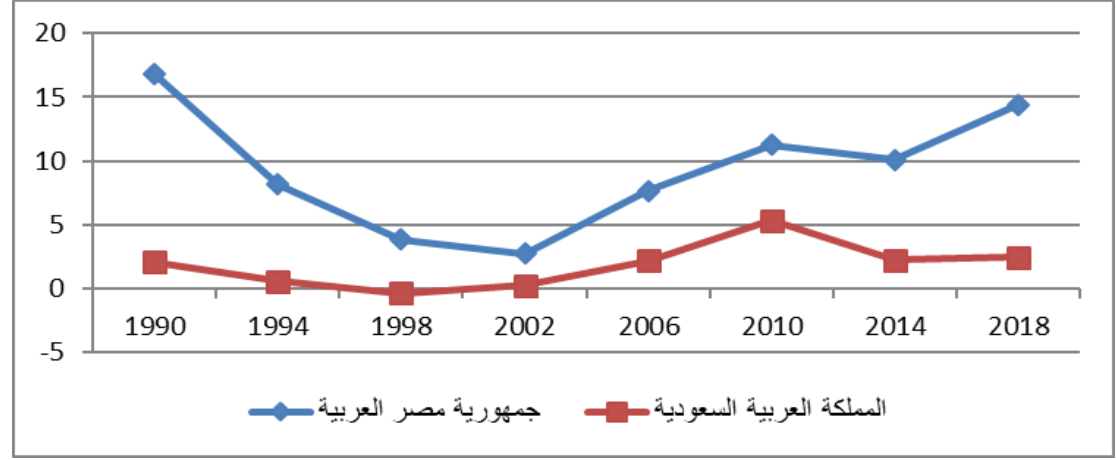

شكل رقم(؛ ): معدل التضخم لجمهورية مصر العربية والمملكة العربية السعودية خلال الفترة

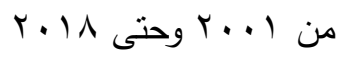

من الجدول (Y) والثكل (Y) يتضح أنه بمقارنة معدل التضخم لكل من جمهورية مصر

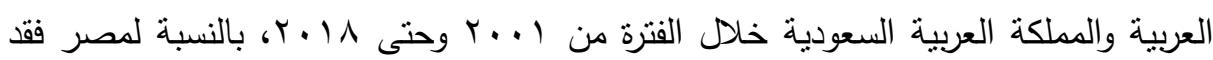

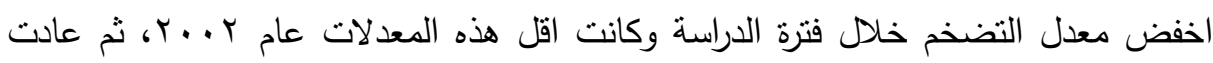

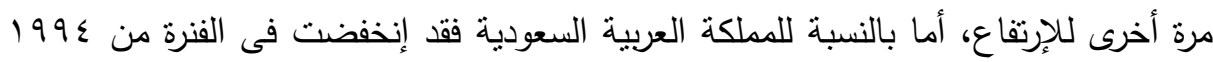

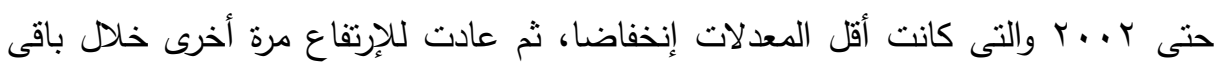

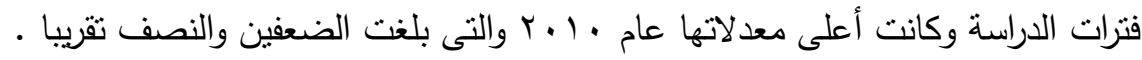
ثالثاً: اختبارات الفروض الإحصائية: يقوم البحث على خمسة فرضيات قام الباحثون باختبار كل منها باستخدام الأساليب المختلفة للتحليل الإحصائي على النحو التالي: الفرض الأول: ينص الفرض الرئيسى الأول الذي قام الباحثون بصياغته في صورته العدمية

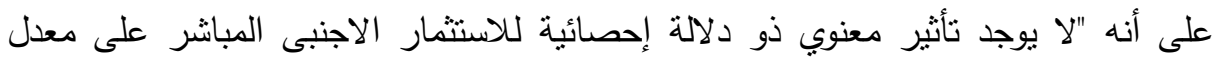
التضخم بجمهورية مصر العربية " ولكي يتم اختبار الفرض قام الباحثون باستخدام تحليل الانحدار الخطي البسيط وذلك بطريقة المربعات الصغرى (OLS) وأسفرت نتائج التحليل الإحصائي للباحثة على ما يلي: 178

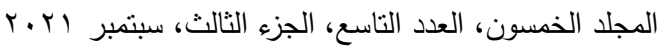

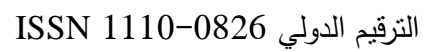

$$
\begin{aligned}
& \text { الترقيم الدولي الموحد الإلكتروني 3178-2636 }
\end{aligned}
$$


جدول(r): اختبار معاملات الانحدار ونتائج الارتباط للفرض الأول

\begin{tabular}{|c|c|c|c|c|c|}
\hline 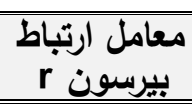 & $\begin{array}{l}\text { القزار عن } \mathbf{\alpha}=\mathbf{0 . 1} \\
\end{array}$ & الالالوية & قيمة t & الانحدار & المستغيل \\
\hline rוז, & معنوي & $\cdot, .91$ & $16 \times 17$ &., .10 & التضخم \\
\hline
\end{tabular}

جدول( )): تحليل التباين ANOVA للفرض الأول

\begin{tabular}{|c|c|c|c|c|}
\hline معامل التحديد & $\begin{array}{c}\text { القزار عن } \\
\alpha=0.1\end{array}$ & مستوي & قيمة F & المتغير التابع \\
\hline$\% 9,1$ & معنوي &., .91 & $T_{6} q \leqslant 0$ & الاستثمار الاجنى المباشر \\
\hline
\end{tabular}

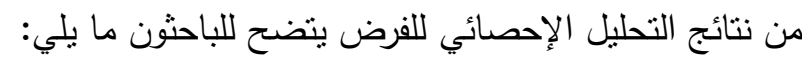

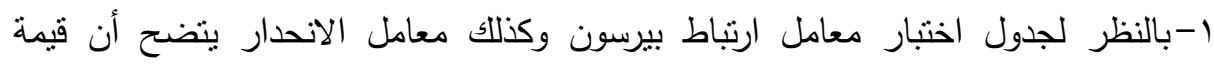

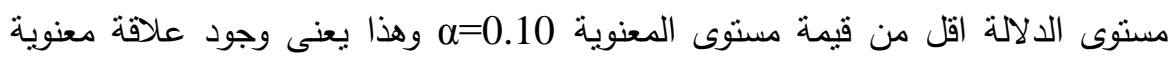

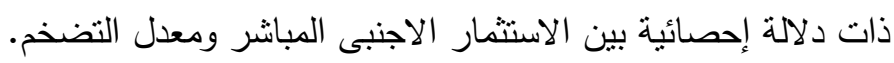
r-كانت إنشارة معامل الانحدار الواردة في النموذج المقدر إنشارة موجبة وهذا يعني وجود علاقة طردية معنوية ذات دلالة إحصائية للاستثمار الاجنبى المباشر على الثئ معدل التضخم.

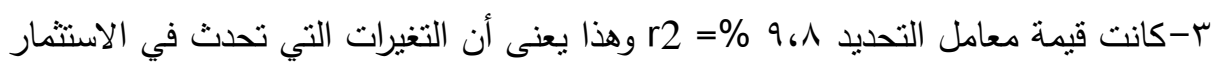
الآجنبى المباشر مسئولة عن تفسير ما نسبته ^،9 \% من معاتهل التغيرات التي تحدث في معدل التضخم، والنسبة الباقية ترجع لوجود عوامل أخرى بالإضافة إلى حد الخطأ العشوائي .

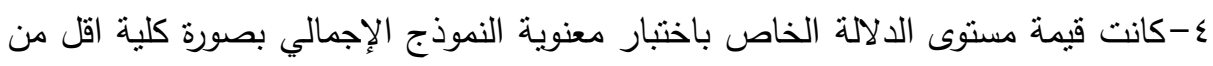
قيمة مسنوى المعنوية المجتمع محل الدراسة.

التزقيم الدولي الترقيم الدولي الموحد الإلكتروني 3178-2636-26 
مما سبق يمكن للباحثة رفض الفرض في الصورة العدمية وقبول الفرض في الصورة البديلة التي نصت علي أنه " يوجد تأثير معنوي ذو دلالة إحصائية للاستثمار الاجنبى فئي

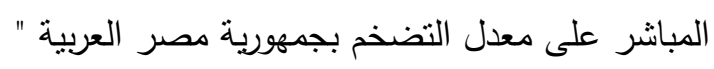

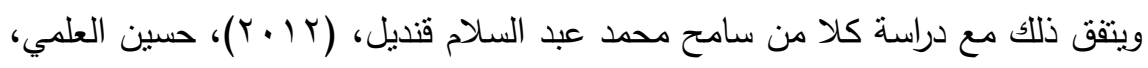

$$
\text { (T) }
$$

الفرض الفرعى الثانى: ينص الفرض الرئيسى الأول الذي قام الباحثن بصياغته في صورته

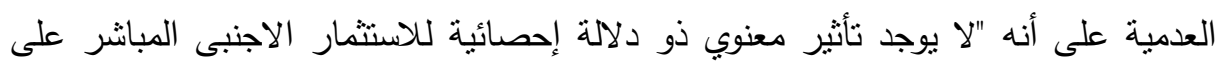

معدل التضخم بالمملكة العربية السعودية "

ولكي يتم اختبار الفرض قام الباحثون باستخدام تحليل الانحدار الخطي البسيط وذلك

بطريقة المربعات الصغرى (OLS) وأسفرت نتائج التحليل الإحصائي للباحثة على ما يلي: بلئ لئي

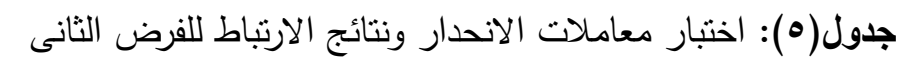

\begin{tabular}{|c|c|c|c|c|c|}
\hline 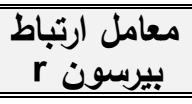 & 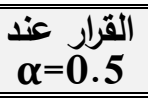 & مستوئي & قيمة t & الاتحدارل & المتغير المستقل \\
\hline 9ץ9, & معنوي & $\cdot, \cdots$ & 0,700 & $\cdot, \cdot 1 T$ & التضخم \\
\hline
\end{tabular}

جدول(؟): تحليل التباين ANOVA للفرض الثانى

\begin{tabular}{|c|c|c|c|c|}
\hline $\begin{array}{c}\text { معامل التحديا } 2 \\
\end{array}$ & 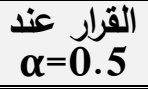 & مستوية & قيمة F & المتغير التابع \\
\hline$\%$ or, & معنوي & $\cdot, \cdots$ & M. & الاستثمار الاجنى \\
\hline
\end{tabular}

$$
\text { من نتائج التحليل الإحصائي للفرض يتضح للباحثون ما يلي: }
$$

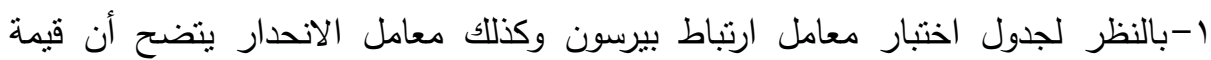
مستوى الدلالة اقل من قيمة مستوى المعنوية 0.05=0 وهذا يعنى وجود علاقة معنوية ذات دلالة إحصائية بين الاستثمار الاجنبى المباشر ومعدل التضخم. 
r-كانت إثنارة معامل الانحدار الواردة في النموذج المقدر إثنارة موجبة وهذا يعني وجود

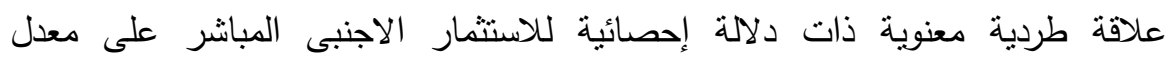

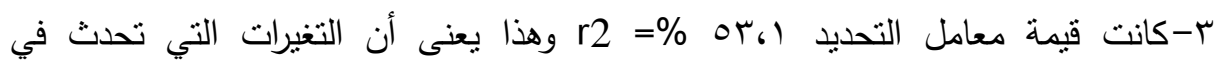

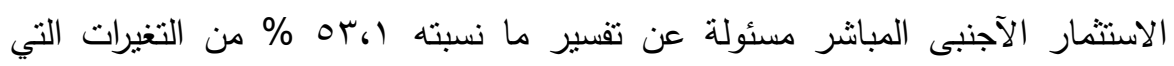

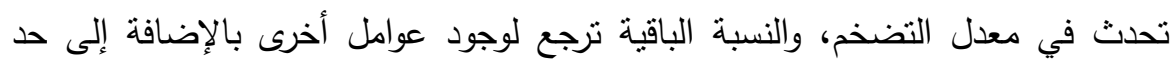

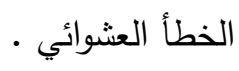

ع-كانت قيمة مستوى الدلالة الخاص باختبار معنوية النموذج الإجمالي بصورة كلية اقل من قيمة مستوى المعنوية م=0.05 وهذا يعنى أن الباحثة يمكنها تعميم نتائج العينة على لئل المجتمع محل الدراسة.

مما سبق يمكن للباحثُون رفض الفرض في الصورة العدمية وقبول الفرض في الصورة

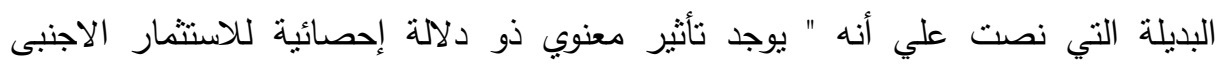

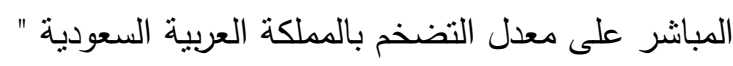

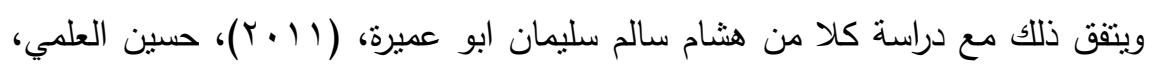
(T)

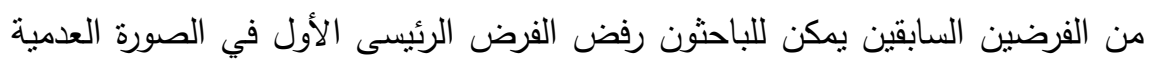

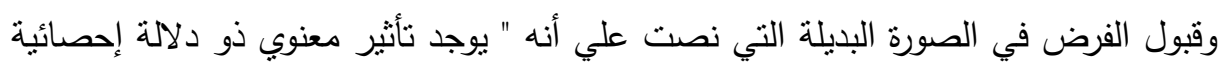
للاستثمار الاجنبى المباشر على معدل التضخم " . ل

$$
\begin{aligned}
& \text { r.r. المجلد الخمسون، العدد الثاسع، الجزء الثالث، سبتمبر }
\end{aligned}
$$

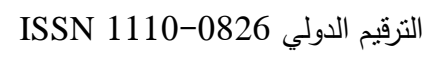

$$
\begin{aligned}
& \text { الترقيم الدولي الموحد الإلكتروني 3178-2636 }
\end{aligned}
$$




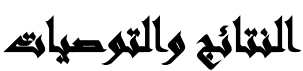

فيما يلى سوف يتم استعراض النتائج التى توصلت إليها الدراسة وأهم التوصيات .

\section{أولاً: نتائج الدراسة :}

بمقارنة التدفقات فى الاستثمار الاجنبى المباشر لكل من جمهورية مصر العربية والمملكة

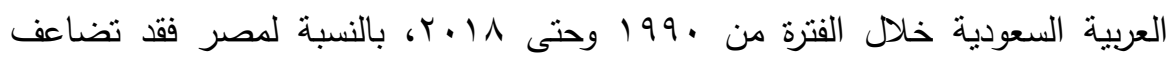
الاستتمار الإجنبى المباشر حتى وصل إلى حوالى ل1 1 ضنعف، وكانت أفضل الفترات عام

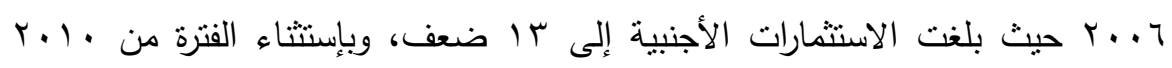

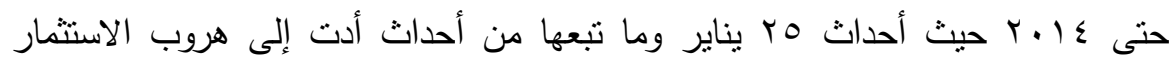
الاجنبى عن مصر ثم عاد بعد ذلك للإزتفاع بصورة جيدة، أما بالنسبة للمملكة العربية

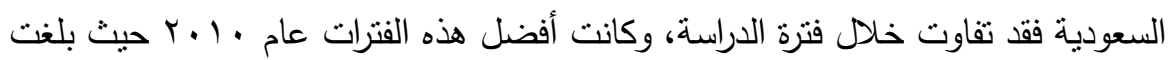

10 همقارنة معدل التضخم لكل من جمهورية مصر العربية والمملكة العربية السعودية خلال

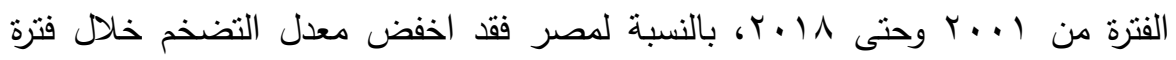

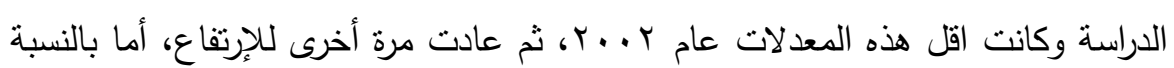

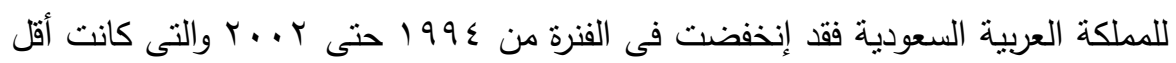
المعدلات إنخفاضا، ثم عادت للإرتفاع مرة أخرى خلال باقى فترات الدراسة وكانت أعلى عنى على أنى

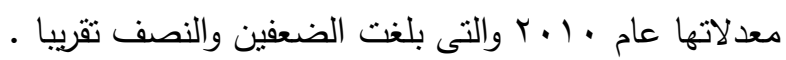
هوجد تأثير معنوي ذو دلالة إحصائية للاستثمار الاجنبى المباشر على بلى معدل التضخم

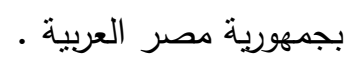
• يوجد نأثير معنوي ذو دلالة إحصائية للاستثمار الاجنبى المباشر على معدل التضخم بالمملكة العربية السعودية .

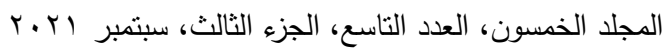

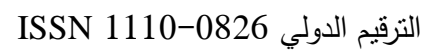

$$
\begin{aligned}
& \text { التزقيم الدولي الموحد الإلكتروني 3178-2636-2082 }
\end{aligned}
$$




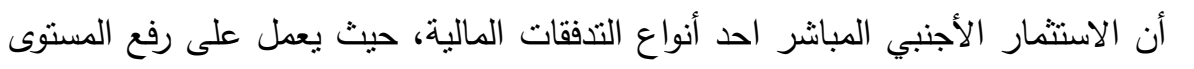

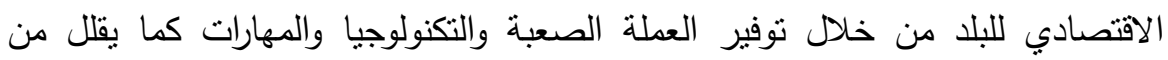
البطالة وتحسين ميزان المدفوعات هذا على المستوى الدا خلي، أما على المستوى الخارجي فهو يعمل على تحرير وعولمة الاقتصاد الدولي، وله أثكال متعددة.

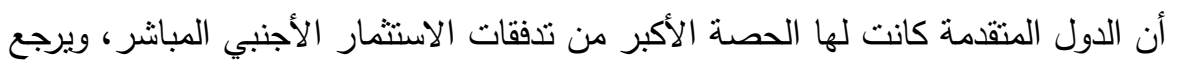

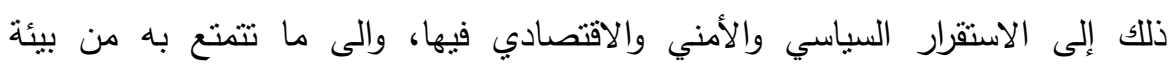

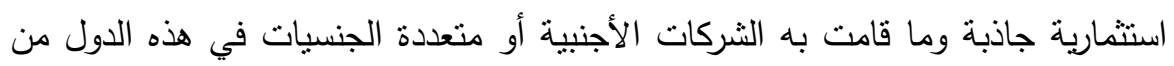
عمليات الاندماج والتملك عبر حدودها من اجل الوحدة الاقتصادية فيما بينها من خلال

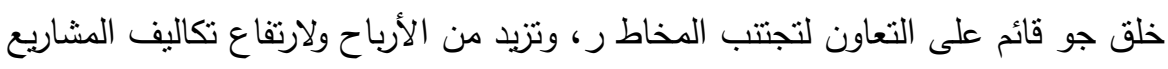
الصناعية والبحث والتطوير ، إضافة إلى ما تحتاجه هذه المشاريع من تكنولوجيا عالمية متطورة . ثانياً: التوصيات: هجب على الدول العربية بشكل عام ودول الدراسة بشكل خاص الاستفادة من تجارب الدول

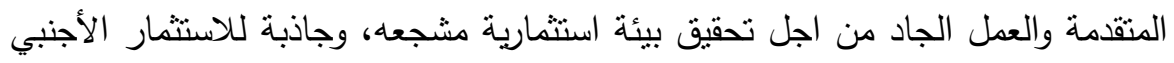
المباشر من خلا توفير الاستقرار الأمني والسياسي والاقتصادي، وتتريع القوانين التي تدعم القطاع الخاص ويمكن من خلالها الحصول على اكبر حجم من تدفقات الاستثمار الأجنبي المباشر، وتوجيهها إلى القطاعات الاقتصادية كافة وعلى رأسها القطاعات القائدة والرائدة فى الاقتصاد، وجعل أثز الاستثمار الأجنبي المبانثر على التتمية الاقتصادية ليس

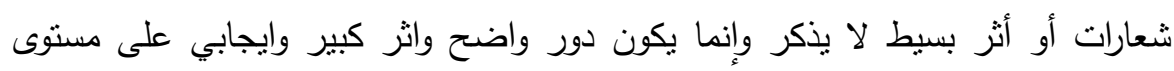

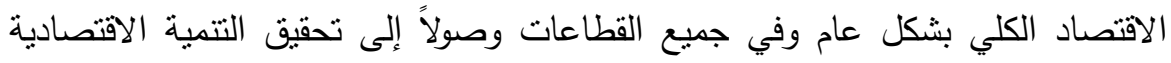

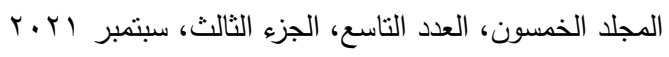

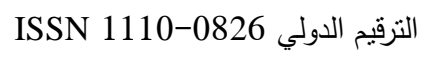

$$
\begin{aligned}
& \text { الترقيم الدولي الموحد الإلكتروني 3178-2636 }
\end{aligned}
$$


• يجب على الحكومة المصرية العمل الجاد من اجل تحقيق الاستقرار الأمني والسياسي

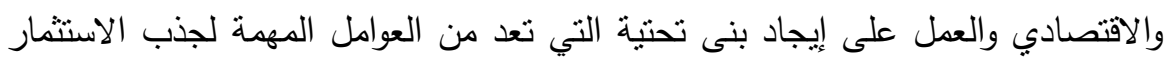
بشكل عام. • ضرورة القضاء على الفساد المالي والإداري في دول المقارنة، من خلال تتديد إجراءات هيئة الرقابة الإدارية والمالية على مؤسسات الدولة والتتسيق بينهم، والاطلاع على التقارير

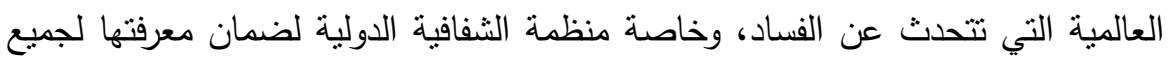
المعلومات من اجل رفع مرتبة مصر والسعودية في المؤشر • • تحسين عمل السياسات المالية والنقدية والتجارية فى جمهورية مصر العردية العربية والمملكة العربية السعودية من اجل تتظيم عمل الاقتصاد ومعالجة المشاكل التي يعاني منها الاقتصاد منل مشاكل التضخم والبطالة وعجز الموازنة العامة والديون وغيرها.

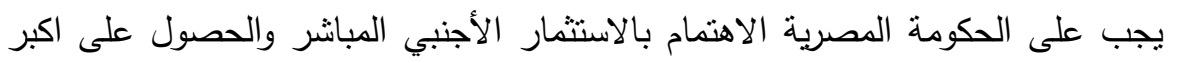
حجم منه وعدم الاعتماد على المساعدات والقروض الخارجية لسد العجز بالموازنة وإقامة

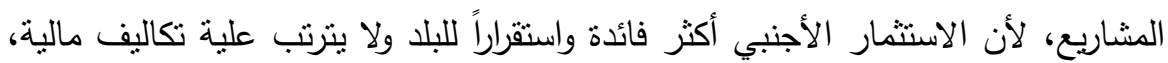
بالإضافة إلى أنه ينقل التكنولوجيا والخبرات الإدارية والمعرفية.

\section{المرالئar}

أحمد، ر. ص. أ. (11 (1): الاستثمار الأجنبي وأثاره : مع دراسة تحليلية في مسودة القانون

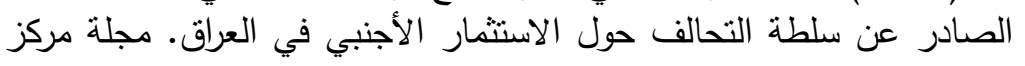

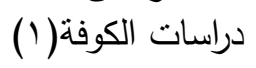

الأسرج، ح. ع. (0. • ץ): سياسة تتمية الاستثمار الاجنبي المباشر إلى دول العالم العربي.

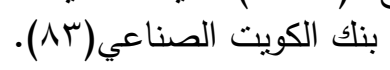

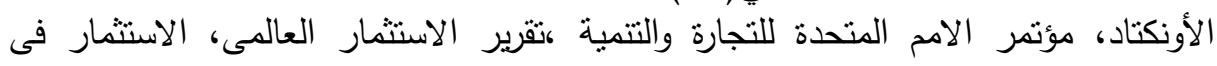

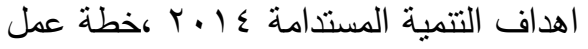

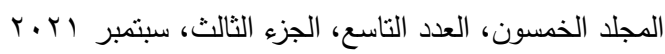

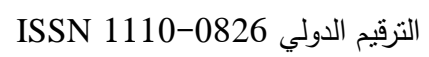

$$
\begin{aligned}
& \text { التزقيم الدولي الموحد الإلكتروني 3178-2636-2082 }
\end{aligned}
$$




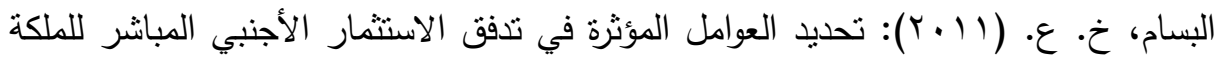

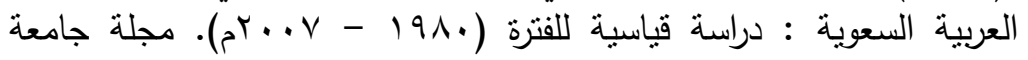

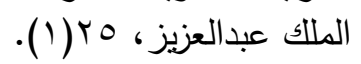

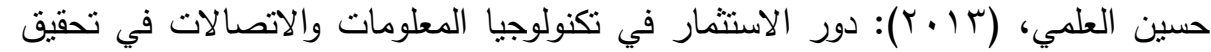
التتمية المستدامة، رسالة ماجستير، مدرسة الدكتوراة : إدنرة الاعمال والتتمية والتية

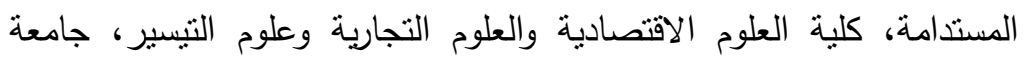

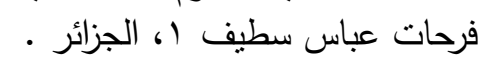

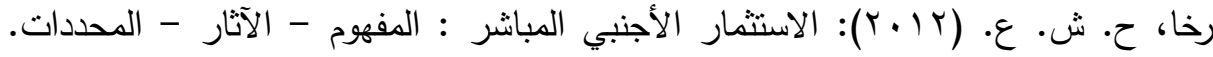

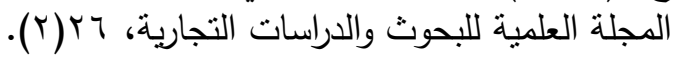

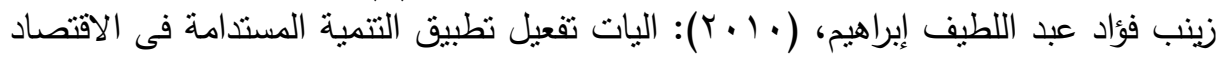

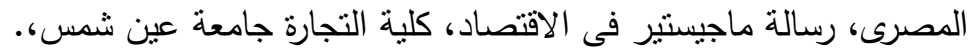

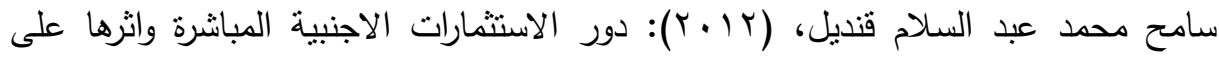

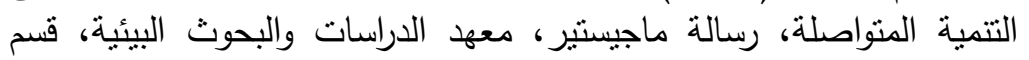

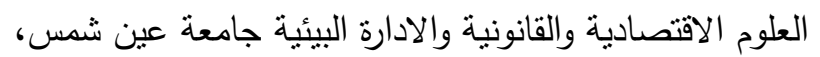

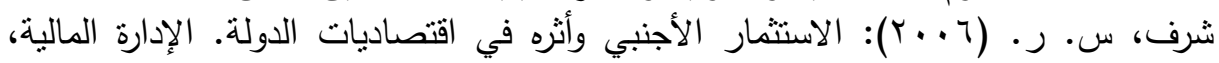

(1) (1)

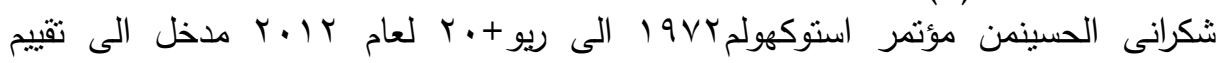

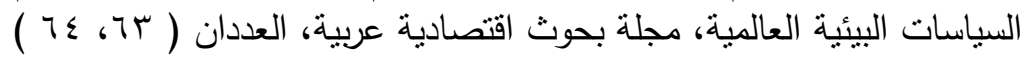

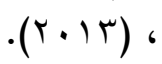

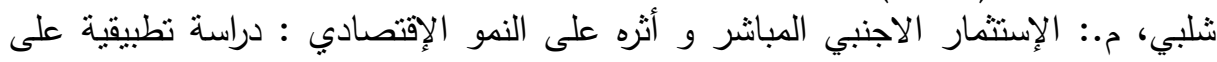

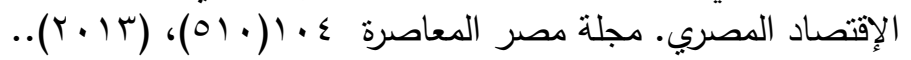

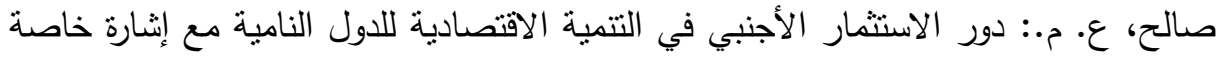

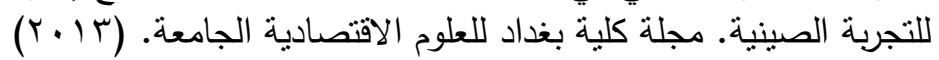

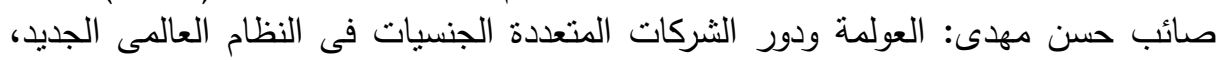

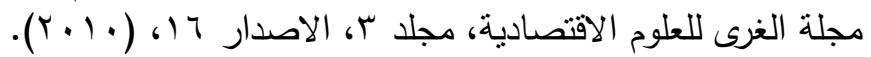

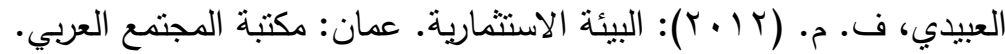

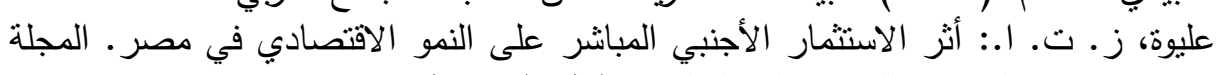

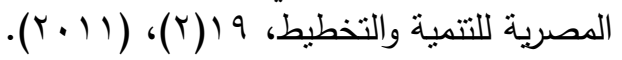

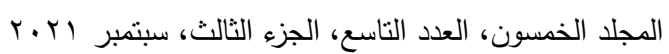

$$
\begin{aligned}
& \text { الترقيم الدولي 0826- ISSN 1110 } \\
& \text { التزقيم الدولي الموحد الإلكتروني 3178-2636 }
\end{aligned}
$$




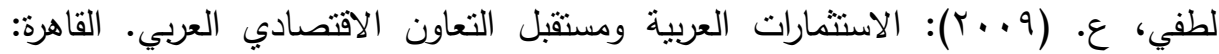
المنظمة العربية للتنمية الإدارية.

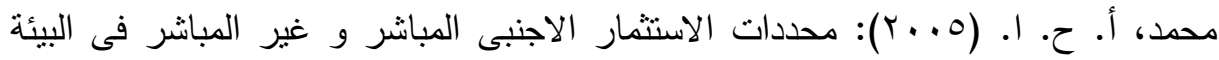
الاقتصادية العربية : دراسة مقارنة ( تركيا - كوريا الجنوبية - مصر الانية ). الاسكندرية الدار الجامعية.

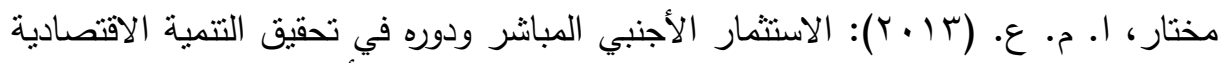

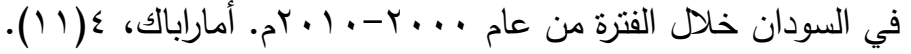

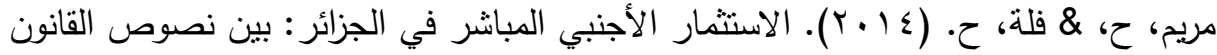

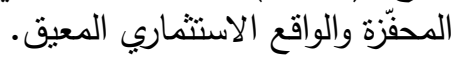

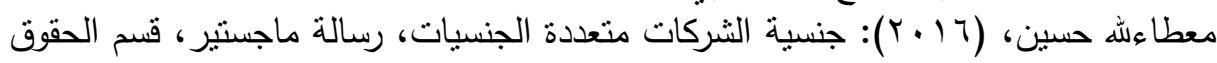

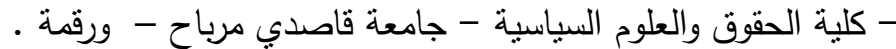

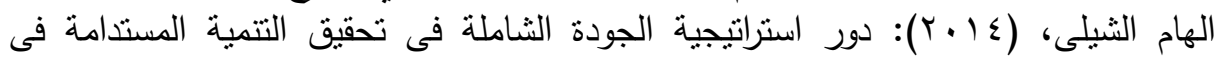

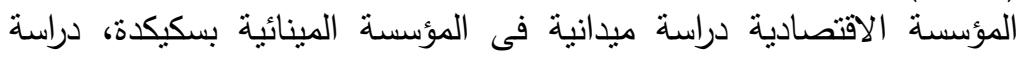
ماجيستير لنيل درجة الماجيستير كلية العلوم الاقتصادية والتجارية وعلوم

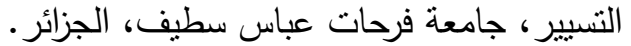

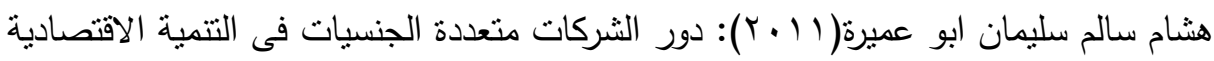

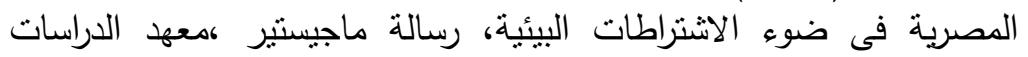
والبحوث البيئية، قسم العلوم الاقتصادية والقانونية والادارة البيئية جامعة عين البية 


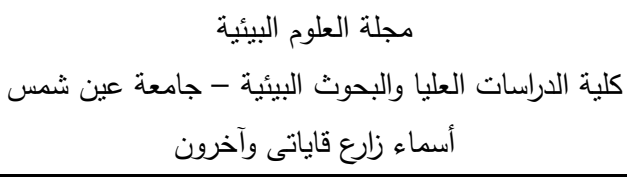

\title{
THE EFFECT OF FOREIGN DIRECT INVESTMENT ON THE INFLATION RATE IN THE ARAB REPUBLIC OF EGYPT AND THE KINGDOM OF SAUDI ARABIA
}

\author{
Asma Z. Qayati ${ }^{(1)}$; Ahmed F. Mandour ${ }^{(2)}$ and Magda M. A. Jibril ${ }^{(2)}$ \\ 1) Post Grad. Student, Faculty of Graduate Studies and Environmental \\ Research, Ain Shams University 2) Faculty of Commerce, Ain Shams \\ University
}

ABSTRACT

The study aimed to measure the impact of foreign investments on economic growth, and the study sought to direct policy makers and decision makers to the important role played by foreign direct investment and its impact on economic growth, through a main goal is to measure the impact of foreign direct investment on the rate of inflation, and the research was adopted On the descriptive analytical approach, which includes the use of the data collection method, where the data of the World Bank was used, and its statistical analysis in order to test the validity of the research hypotheses.

\section{The research found:}

- There is a significant statistical impact of foreign direct investment on the inflation rate in the Arab Republic of Egypt.

- There is a significant statistical impact of foreign direct investment on the inflation rate in the Kingdom of Saudi Arabia.

- Foreign direct investment is one of the types of financial flows, as it works to raise the country's economic level by providing hard currency, technology and skills, as well as reducing unemployment and improving this balance of payments at the internal level, while at

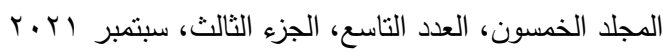

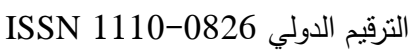

$$
\begin{aligned}
& \text { الترقيم الدولي الموحد الإلكتروني 3178-2636 }
\end{aligned}
$$




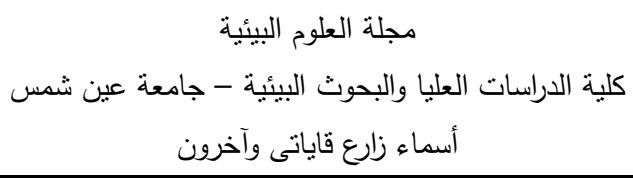

the external level it works to liberalize and globalize the international economy. Multiple shapes

\section{The most important recommendations:}

- The Egyptian government must work hard in order to achieve security, political and economic stability, and work to find infrastructure, which is one of the important factors to attract investment in general.

- The necessity of eliminating financial and administrative corruption in the comparison countries, through tightening the procedures of the Administrative and Financial Control Authority on state institutions and coordinating between them, and reviewing global reports that talk about corruption, especially Transparency International, to ensure that it knows all the information in order to raise the rank of Egypt and Saudi Arabia in the index.

- Improving the work of the financial, monetary and commercial policies in the Arab Republic of Egypt and the Kingdom of Saudi Arabia in order to organize the work of the economy and address the problems that the economy suffers from such as problems of inflation, unemployment, public budget deficit, debts and others.

key words: Foreign Direct Investment - Inflation Rate - Egypt - Saudi Arabia

$$
\begin{aligned}
& \text { المجلد الخمسون، العدد الثاسع، الجزء الثالث، سبتمبر (Y. r. }
\end{aligned}
$$

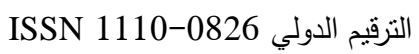

$$
\begin{aligned}
& \text { الترقيم الدولي الموحد الإكتروني 3178-2636 }
\end{aligned}
$$

